Neurochem Int. 2011 August ; 59(2): 122-137. doi:10.1016/j.neuint.2011.03.025.

\title{
Role of oxidative stress in epileptic seizures
}

\author{
Eun-Joo Shin ${ }^{\mathrm{a}}$, Ji Hoon Jeong ${ }^{\mathrm{b}}$, Yoon Hee Chung ${ }^{\mathrm{c}}$, Won-Ki Kim ${ }^{\mathrm{d}}$, Kwang-Ho Ko ${ }^{\mathrm{e}}$, Jae- \\ Hyung Bach $^{\mathrm{a}}$, Jau-Shyong Hong ${ }^{\dagger}$, Yukio Yoneda ${ }^{9}$, and Hyoung-Chun Kima, ${ }^{\star}$ \\ aNeuropsychopharamcology and Toxicology Program, College of Pharmacy, Kangwon National \\ University, Chunchon 200-701, South Korea \\ bDepartment of Pharmacology, College of Medicine, Chung-Ang University, Seoul 156-756, \\ South Korea \\ 'Department of Anatomy, College of Medicine, Chung-Ang University, Seoul 156-756, South \\ Korea \\ dDepartment of Neuroscience, College of Medicine, Korea University, Seoul 136-705, South \\ Korea \\ ePharmacology Laboratory, College of Pharmacy, Seoul National University, Seoul 143-701, \\ South Korea \\ fNeuropharmacology Section, Laboratory of Pharmacology and Chemistry, National Institute of \\ Environmental Health Sciences, National Institutes of Health, Research Triangle Park, North \\ Carolina 27709, USA \\ gLaboratory of Molecular Pharmacology, Division of Pharmaceutical Sciences, Kanazawa \\ University Graduate School of Natural Science and Technology, Kanazawa, Ishikawa 920-1192, \\ Japan
}

\begin{abstract}
Oxidative stress resulting from excessive free-radical release is likely implicated in the initiation and progression of epilepsy. Therefore, antioxidant therapies aimed at reducing oxidative stress have received considerable attention in epilepsy treatment. However, much evidence suggests that oxidative stress does not always have the same pattern in all seizures models. Thus, this review provides an overview aimed at achieving a better understanding of this issue. We summarize work regarding seizure models (i.e., genetically epilepsy-prone rats, kainic acid, pilocarpine, pentylenetetrazol, and trimethyltin), oxidative stress as an etiologic factor in epileptic seizures (i.e., impairment of antioxidant systems, mitochondrial dysfunction, involvement of redox-active metals, arachidonic acid pathway activation, and aging), and antioxidant strategies for seizure treatment. Combined, this review highlights pharmacological mechanisms associated with oxidative stress in epileptic seizures and the potential for neuroprotection in epilepsy that targets oxidative stress and is supported by effective antioxidant treatment.
\end{abstract}

\section{Keywords}

Epileptic seizures; Oxidative stress; Antioxidant strategies; Animal models

\footnotetext{
"Corresponding author: Prof. Hyoung-Chun Kim, Neuropsychopharmacology and Toxicology Program, College of Pharmacy, Kangwon National University, Chunchon 200-701, South Korea. Tel: +82-33-250-6917, fax: +82-33-255-7865,

kimhc@kangwon.ac.kr.
} 


\section{Introduction}

Epilepsy has plagued humanity for centuries. It was probably first described in ancient Egyptian writings around 2000 BC and was a popular topic of the Greek and Roman scholars. The "sacred disease" or "falling sickness," as it was frequently called, was closely identified with supernatural forces and was considered a manifestation of the gods and spirits. The modern era of epilepsy began with the writings of Jackson in the late 1870s (Jackson, 1879). His extensive treatise established the neuroanatomic basis for epileptic phenomena. Since the introduction of eletroencephalography in the 1930s (Gastaut, 1950), the understanding of the basic neurophysiology of the disorder has greatly expanded. Improved understanding has resulted in the development of a large number of potent and specific drugs for various seizure types and has been the basis for rational therapeutics and patient monitoring. Despite the increasing number and variety of anti-epileptic drugs, more than $30 \%$ of cases of epilepsy are medically intractable (Kwan and Brodie, 2000), with temporal lobe epilepsy (TLE) having one of the worst prognoses among epileptic disorders. There is usually a latent period of several years between the initial precipitating injury and the emergence of chronic TLE characterized by spontaneous recurrent motor seizures originating from temporal lobe foci (Devinsky, 2004). Furthermore, TLE is frequently associated with hippocampal sclerosis, mainly exemplified by significant neurodegeneration in the dentate hilus and the CA1 and CA3 regions (Sloviter, 2005). Moreover, anti-epileptic drugs merely provide symptomatic treatment without having any influence on disease course. Thus, there is a pressing need to develop alternative therapeutic approaches that prevent epileptogenesis after status epilepticus (SE).

In the modern era, epilepsy is the most frequent neurodegenerative disease after stroke. It afflicts more than 50 million people worldwide (Strine et al., 2005). At least 6\% of the population is said to suffer one isolated seizure episode during their lifetime. Over $90 \%$ of epileptics suffer from generalized tonic-clonic seizures, and many suffer from multiple forms of the disorder.

Brain injury resulting from seizures is a dynamic process that comprises multiple factors contributing to neuronal cell death. These may involve genetic factors, excitotoxicityinduced mitochondrial dysfunction, altered cytokine levels, and oxidative stress (Ferriero, 2005). Seizure-like activity at the cellular level initiates significant influx of calcium via voltage-gated and N-methyl-D-aspartate (NMDA)-dependent ion channels (Van Den Pol et al., 1996). Elevated intracellular ions lead to biochemical cascades, which trigger acute neuronal death after SE (Fujikawa et al., 2000). In addition, high levels of intracellular calcium can induce reactive oxygen species (ROS).

ROS, including superoxide radical $\left(\cdot \mathrm{O}_{2}^{-}\right)$, hydrogen peroxide $\left(\mathrm{H}_{2} \mathrm{O}_{2}\right)$, hydroxyl radical $(\cdot \mathrm{OH})$, and singlet oxygen $\left({ }^{1} \mathrm{O}_{2}\right)$, are generated during normal cellular metabolism (Kontos, 1989; Beit-Yannai et al., 1997). Physiological levels of ROS can be scavenged by enzymatic [e.g., superoxide dismutase (SOD), catalase (CAT), glutathione peroxidase (GPx), glutathione reductase (GR), and peroxiredoxins (Prxs)] and non-enzymatic [e.g., vitamin C, vitamin E, and reduced form of glutathione (GSH)] antioxidant defense systems. However, excessive ROS levels due to increased ROS production, decreased antioxidant defense ability, or both leads to oxidative stress (Winyard et al., 2005). In addition, excess ROS further reacts with nitric oxide (NO) to generate reactive nitrogen species (RNS) such as peroxynitrite $\left(\mathrm{ONOO}^{-}\right.$; Brown and Borutaite, 2001).

The brain is particularly susceptible to oxidative stress because it utilizes the highest amount of oxygen compared with other bodily organs. The brain also contains high concentrations of polyunsaturated fatty acids that are prone to lipid peroxidation, is rich in iron, which can 
catalyze hydroxyl radical formation, and is low in CAT activity (e.g., 10\% that of the liver; Halliwell, 1999; Mariani et al., 2005; Jellinger, 2003). Oxidative stress results in functional cellular disruption and cellular damage and may cause subsequent cell death via oxidation of biomolecules such as proteins, lipids, and nucleotides. Protein oxidation leads to functional changes or deactivation of various enzymes (Stadtman, 2001). Lipid peroxidation causes membrane structure alterations that affect membrane fluidity and permeability and membrane protein activity (Wong-ekkabut et al., 2007). Oxidative stress is involved in the pathogenesis of a number of neurologic conditions and neurodegenerative disorders, including Alzheimer's disease, Parkinson's disease, amyotrophic lateral sclerosis, and epilepsy (Perry et al., 2002; Migliore et al., 2005; Ashrafi et al., 2007).

However, the role of oxidative stress in epilepsies has only recently begun to be recognized (Ashrafi et al., 2007). Studies have focused on elucidating whether prolonged seizure activity in animals results in increased ROS production and whether oxidative injury contributes to seizure-induced brain damage. ROS formation occurs when unpaired electrons escape the electron transport chain and react with molecular oxygen, thus generating superoxide. Superoxide can react with DNA, proteins, and lipids and plays an important role in many physiological and pathophysiological conditions. The maintenance of low ROS levels is critical to normal cell function, and therefore, prolonged increases in ROS carry an inherent risk of increasing neurodegeneration such as that seen in epilepsy.

This review outlines studies supporting the emerging recognition of the role of oxidative stress in epileptic conditions. Evidence for the production and consequences of acute and chronic oxidative stress in various animal models of epilepsy are reviewed, and damage to proteins, lipids, and antioxidant defenses is considered. Oxidative stress in relation to cell death or consequences of epileptic seizures is given attention because neuronal cells are considered vulnerable to oxidative damage and a contributing factor in epileptogenesis. In addition, regulation of oxidative stress with natural and chemical treatments as a means of attenuating epileptogenesis and seizure initiation is discussed.

\section{Seizure-induced oxidative damage}

\subsection{Genetically epilepsy-prone rats (GEPRs)}

Genetically epilepsy-prone rats (GEPRs) are models of generalized tonic/clonic epilepsy and have been used to study basic mechanisms of human epilepsy. GEPRs exhibit audiogenic seizures in response to acoustic stimulation (AS; Dailey et al., 1989). Two strains have been developed: a) moderate-seizure GEPRs (GEPR-3s), which have AS-induced clonic seizures, and b) severe-seizure GEPRs (GEPR-9s), which undergo severe seizures, culminating in tonic hindlimb extension (Dailey et al., 1989). Although the majority of studies on GEPRs have induced seizures using AS, GEPRs are innately hypersensitive to a variety of nonaudiogenic convulsant treatments, including fluothyl, pentylenetetrazol, KA administration, electroshock, and kindling (Browning et al., 1990; Shin et al., 2008b; Millan et al., 1991). In fact, GEPRs show a greater propensity for generalized seizures via nonaudiogenic stimuli.

Physiological and biochemical traits in GEPRs that are not found in the parent strain (Sprague-Dawley; SD) are presumed to be abnormal (Dailey et al., 1989) and include dysfunctional noradrenergic, serotonergic, GABAergic, and glutamatergic neurons (Dailey et al., 1989; Shin et al., 2009a; Ryu et al., 2000). These abnormalities may be related to oxidative stress (Troadec et al., 2001; Shin et al., 2008b).

Shin et al. (2008b) demonstrated for the first time that GEPR-9 hippocampal development is accompanied by oxidative stress and that GEPR-9s do not compensate for a breakdown in 
GPx enzymatic activity. GPx activity was more pronounced in SD rats than in GEPR-9s, which had decreased GPx and GSH/an oxidized form of glutathione (GSSG) ratio and increased GSSG, lipid peroxidation, and protein oxidation, suggesting that the enhanced oxidative burden in GEPR-9s may be attributable to their failure to respond to reduced GPx, combined with the perturbed glutathione status in this strain (refer to Fig. 1). We also found that GEPR-9s had greater seizure sensitivity in response to KA compared with SD rats and that the seizure activity was positively correlated with hippocampal oxidative stress markers such as MDA and protein carbonyl. A KA-induced negative correlation between seizure activity and GSH/GSSG ratio or GPx activity suggested that convulsive behaviors may impair glutathione homeostasis. These findings are most pronounced in adult GEPR-9s (Shin et al., 2008b).

Our findings also indicate that GPx is not upregulated in response to KA-induced oxidative stress, especially in adult GEPR-9s (Shin et al., 2008b). GPx and CAT levels in neuronal tissue appear too low for the prevention of peroxide-induced lesions. Furthermore, neuronal cell membranes contain high levels of polyunsaturated fatty acids (Halliwell, 1992). Thus, GEPR-9 brain cells may be extremely susceptible to peroxidative damage. We also agree with speculation that the early increase in lipid peroxidation and protein oxidation in adult GEPR-9s directly correspond with KA-induced pathology, whereas the prolonged elevation of GPx enzyme activity in SD rats may result from subsequent glial activity (Shin et al., 2008b).

\subsection{Kainic acid (KA)-induced seizures}

The KA seizure model is particularly useful for the study of the evolution, propagation, and pathological consequences of epileptic discharge in the limbic system. Activation of the KA subtype of ionotropic gluatamate receptors results in sustained epileptic activity in the hippocampus, followed by a selective pattern of neuropathology that is similar to human TLE (Ben-Ari, 1985; Ben-Ari et al., 2000). It clearly fulfils the criteria for human TLE as (a) the hippocampus, amygdala, and other limbic structures play a central role in the symptomatology; (b) the pattern of brain damage is reminiscent of Ammon's horn sclerosis, with a similar gradient of vulnerability; and (c) spontaneous seizures with limbic symptomatology are consistently noted following parenteral or intracerebral KA. The KA model may shed some light on TLE in humans. For example, work with this model led to the observation that selective seizure-related damage in CA3 can be produced without hypoxia or hypercapnia, suggesting that restricted paroxysmal discharge may produce selective seizure-related localized damage in the hippocampus. Conversely, the damage noted in the human temporal cortex may be due to general disturbances associated with the seizures (Ben-Ari 1985).

KA increases ROS production, mitochondrial dysfunction, and apoptosis in neurons in many regions of the brain, particularly in the hippocampal regions of CA1 and CA 3 and in the dentate hilus. Oxidative stress and excessive glutamate receptor activation represent sequential, as well as interacting, factors that converge as a final common pathway for neuronal vulnerability (Coyle and Puttfarcken, 1993). Growing evidence indicates that ROS and RNS formation is a consequence of glutamate receptor-mediated neurotoxicity (Dugan et al., 1995). Activation of glutamate receptors and consequent calcium-dependent depolarization of mitochondrial membrane potential lead to incomplete $\mathrm{O}_{2}$ consumption, reduced production of ATP, overproduction of ROS, NO, and peroxynitrite, and consequent damage of cell structures including lipids, proteins, and DNA. Thus, impaired mitochondrial respiratory chain function and the ensuing lipid peroxidation associated with seizure activity may precede neuronal damage and death in vulnerable brain regions (Frantseva et al., 2000). 
In our previous study, we reported elevation of protein oxidation and lipid peroxidation in the hippocampus at early time points (i.e., 4 and $24 \mathrm{~h}$ ) post-KA (Kim et al., 1997). In another report, Tang et al. (1998) provided data suggesting that 8-hydroxy-2deoxyguanosine (8-OHdG), an oxidative marker for DNA damage, may be elevated in the hippocampus and cerebral cortex $8 \mathrm{~h}$ after KA treatment.

The precise molecular mechanisms of seizure-induced neuronal death remain unknown, although there is experimental evidence of ROS involvement (Kovacs et al., 2002). Oxidative stress induced by mitochondrial production of superoxide radicals plays an important role in excitotoxicity resulting from KA-induced seizures (Liang et al., 2000; Patel, 2004). ROS derived from superoxide radicals, such as hydroxyl radicals, can oxidize mitochondrial proteins, DNA, and lipids, resulting in cell damage (Chuang et al., 2009; Patel, 2004). The increase in superoxide production and oxidative DNA damage following KA administration are indications of KA-induced mitochondrial and oxidative damage (Liang and Patel, 2006, Patel, 2004; Kim et al., 2000a). Similarly, KA exposure can significantly increase the production of malondialdehyde (MDA) and 4-hydroxy-alkenals, suggesting an increase in lipid peroxidation (Liang and Patel, 2006; Shin et al., 2008a; Ong et al., 2000). In addition to the increase in lipid peroxidation, systemic administration of KA also caused a decrease in reduced form of glutathione (GSH) levels in the hippocampus (Shin et al., 2008b). Intravenous GSH administration protected against KA-induced neuronal loss in the hippocampus and subsequent development of edema (Saija et al., 1994).

Melatonin also prevented the neurotoxic effects of ROS generated by KA receptor activation through an increase in intracellular GSH (Floreani et al., 1997). Therefore, GSH may protect neuronal cells against KA neurotoxicity through a mechanism associated with ROS scavenging (Kim et al., 2000a; Kitayama et al., 1999; Ogita et al., 2001; Yoneda et al., 2001).

It is generally accepted that oxidative stress upregulates the expression of inflammatory genes via activation of redox-responsive transcription factors. Indeed, activation of activator protein-1 (AP-1) and nuclear factor $\mathrm{kB}(\mathrm{NF}-\mathrm{kB})$ is considered to contribute to the general regulation of a number of inflammatory genes by cellular oxidative stress and/or intracellular glutathione levels (Schreck et al., 1992; Arrigo, 1999).

A previous study showed that prolonged GSH depletion may lead to sensitization of the KA receptor to potentiate AP-1 DNA-binding activity in the murine hippocampus (Kitayama et al., 1999; Ogita et al., 2001; Yoneda et al., 2001), suggesting that endogenous GSH may be partly involved in the underlying molecular mechanisms of transcription control by KA (Kitayama et al., 1999; Ogita et al., 2001; Yoneda et al., 2001). Changes in AP-1 DNAbinding activity were qualitatively similar to those observed with NF-kB in the adult rat brain (Rong and Baudry, 1996).

NF-kB is a transcription factor that can be activated by oxidative stress produced by extracellular stimuli and inhibited by the antioxidants pyrrolidine dithiocarbamate (PDTC) and $\mathrm{N}$-acetylcysteine (Schreck et al., 1992).

An earlier report showed a KA-induced increase in NF-kB DNA binding activity in the hippocampus and piriform cortex (Rong and Baudry, 1996). It is generally recognized that increased NF-kB levels in nuclear extracts reflect increased translocation of the factor following its dissociation from its endogenous inhibitor I-kB (Ghosh and Baltimore, 1990). The dissociation can be triggered by oxygen free radicals, among other factors, (Schreck et al., 1991), and NF-kB is widely viewed as an oxidative stress-responsive factor. Therefore, increased oxidative stress during seizure activity leads to NF-kB activation, possibly as an attempt by neurons to defend against the toxic effects of free radicals (Rong and Baudry, 
1996). Shin et al. (2004) observed that treatment with PDTC, an inhibitor of NF-kB, consistently blocked KA-induced neurotoxicity (e.g., seizures, increases in lipid peroxidation and protein oxidation, and hippocampal neuronal loss) in rats via activation of the adenosine A1 receptor.

\subsection{Pilocarpine-induced seizures}

The acute administration of high dose pilocarpine in rodents is an experimental model largely used to study the pathophysiology of seizures (de Freitas et al., 2003). The epilepsy model induced by high-dose pilocarpine has revealed behavioral and electroencephalographic alterations that are similar to those in human TLE (Turski et al., 1983). The precise mechanism of pilocarpine-induced neurotoxic seizures is unclear. It is currently hypothesized that excitotoxic stimulation by a high dose of pilocarpine results in pathological increases in neuronal lesions in response to excess ROS production. Formation of lipid peroxidation and nitrite in the hippocampus, striatum, and frontal cortex are increased during pilocarpine-induced seizures, suggesting possible neuronal damage (Freitas et al., 2004).

Pilocarpine-induced increased oxidative stress could be reflected in direct activation of some antioxidant enzymes. Under normal conditions, there is a steady-state balance between the production of ROS and their destruction by antioxidant systems. However, this balance can be broken either by increased ROS production or by a decrease in cellular antioxidant systems. Pilocarpine-induced seizures produce several changes in variables related to the generation and elimination of oxygen free radicals in adult rats (Pazdernik et al., 2001). Seizures alter brain antioxidant defenses, and there may be extensive participation of enzymes in seizures. A steady-state level of superoxide and $\mathrm{H}_{2} \mathrm{O}_{2}$ is always present in cells as a result of normal metabolism. SOD and CAT are responsible for degradation of superoxide and $\mathrm{H}_{2} \mathrm{O}_{2}$, respectively, and the balance between these antioxidant enzymes is relevant for cell and neuronal functions (Bellissimo et al., 2001; Pazdernik et al., 2001). A previous investigation reported that an increase in free radical scavenging enzyme antioxidant activities (i.e., CAT, SOD, and GPx) was also observed after pilocarpine treatment, suggesting that brain cells try to counteract pilocarpine-induced ROS overproduction (Tejada et al., 2007).

Freitas et al. (2005) suggested that important factors contributing to pilocarpine-induced seizure are GSH concentration, lipid peroxidation, and nitrite content. They showed evidence that neuronal damage in the hippocampus results from a decrease in GSH concentration and increases in lipid peroxidation and nitrite content. GSH level and CAT activity in the hippocampus are involved in mechanisms responsible for eliminating oxygen free radicals during the establishment of SE. In contrast, no correlation between SOD and CAT activities was observed. Unaltered SOD activity is related to mechanisms involved in the initiation and/or propagation of seizures induced by pilocarpine. These results are in agreement with another study showing unaltered SOD activity $24 \mathrm{~h}$ after pilocarpine treatment, suggesting that SOD activity only changes during the initiation of seizures (Hussain et al., 1995).

\subsection{Pentylentetrazol (PTZ)-induced seizures}

PTZ is a selective blocker of the $\mathrm{GABA}_{\mathrm{A}}$ receptor chloride ionophore complex (Huang et al., 2001). It has convulsant effects after repeated or single administration and it affects several neurotransmitter systems, such as GABAergic, adenosinergic (Pagonopoulou and Angelatou, 1998), and glutamatergic systems (Ekonomou and Angelatou, 1999). After PTZinduced seizures, significant decreases in GSH, GSSG, cysteine, and protein thiols as well as increases in the protein carbonyl and protein disulfides levels were observed in the mouse 
cerebral cortex (Patsoukis et al., 2004a). Previous work in the mouse hippocampus showed that protein thiol levels were decreased without significant alterations of GSH and GSSG, while protein disulfides, MDA equivalent, and carbonyl levels were increased in the time period shortly after a single treatment with PTZ (Patsoukis et al., 2004b).

A previous demonstration showed that a single convulsive dose of PTZ resulted in significant changes in many parameters such as $\mathrm{GABA}_{\mathrm{A}}$ receptor density and function (Pagonopoulos and Angelatou, 1998), whole brain hydroxyl radicals (Rauca et al., 1999), and free fatty acid and GPx activity in specific brain areas (Eracovic et al., 2003). Moreover, acute PTZ-induced seizures caused a dramatic elevation (5-fold) of NO in the cerebral cortex (Bashkatova et al., 2003). PTZ-induced reductions in total SOD activity and lipid antioxidant (a-tocopherol) content were observed in rat brain homogenates (Rauca et al., 2004).

\subsection{Trimethyltin (TMT)-induced seizures}

An earlier study characterized an alternative TLE animal model induced by TMT treatment (Imai et al., 2001). Systemic TMT administration in rats caused a pattern of hippocampal damage, mainly in the CA3 region of the hippocampus, and produced phenotypes similar to those of some human epileptic patients, including seizure susceptibility, hyperactivity, and aggression (Dyer et al., 1982; Ishida et al., 1997).

Additionally, TMT has been shown to produce relatively selective neuronal damage, similar to that produced by KA. Although TMT and KA have different time courses of seizure induction and pathologic changes (Sloviter et al., 1986), the two agents may share a common mechanism for the production of the observed hippocampal lesions. Both TMT and KA intoxications have been shown to result in behavioral symptoms that include seizures, which may be related to their interaction with activators of the endogenous excitatory transmitter systems (Kim et al. 1998; Patel et al., 1990; Sperk, 1994).

TMT increases the concentration of free intracellular $\mathrm{Ca}^{2+}$ by promoting the influx of extracellular $\mathrm{Ca}^{2+}$ and the release of $\mathrm{Ca}^{2+}$ from intracellular stores (Komulainen and Bondy, 1987). This increased $\mathrm{Ca}^{2+}$ concentration activates proteases and other degradative enzymes, which in turn promote the conversion of xanthine dehydrogenase to xanthine oxidase, initiating the production of superoxide radicals. Additionally, superoxide radicals can react directly with $\mathrm{NO}$ to form peroxynitrite anions, which are protonated at cellular $\mathrm{pH}$ to produce peroxynitrous acid, which rapidly forms hydroxyl radicals (Oury et al., 1993).

Our previous study clearly demonstrated that the systemic administration of TMT resulted in a significant increase in the formation of hydroxyl radicals, MDA, and protein carbonyl in the rat hippocampus (Shin et al., 2005). These changes were most pronounced in the early stages after TMT administration. These findings agree with the results of Ali et al. (1992), who showed that ROS were elevated in the mouse hippocampus in the early stages ( $24 \mathrm{~h}$ and $48 \mathrm{~h}$ ) after TMT injection. More importantly, TMT induced a persistent disruption of glutathione homeostasis; the ratio of GSH to GSSG, glutathione-like immunoreactivity, and GPx and GR protein expression levels were all decreased in the rat hippocampus. We have also demonstrated that ascorbate treatment attenuates TMT-induced neurotoxic changes, as seen in seizure activity and in changes of all biomarkers, suggesting that TMT produces the neurotoxic insult, at least in part, via oxidative stress in the brain. 


\section{Causes of oxidative stress in epileptic seizures}

\subsection{Impairment of antioxidant systems}

Seizure generation may be related to the homeostatic imbalance of antioxidants and oxidants. To date, various experimental seizure models have been developed to investigate the role of endogenous antioxidants in response to excitotoxic oxidative stress. Impairment of endogenous antioxidant factors against oxidative stress is involved in seizure generation. Antiepileptic drugs, at least in part, impair antioxidant systems. The ability of antioxidants to attenuate seizure generation and the accompanying changes in oxidative burden further support an important role of antioxidants as having putative antiepileptic potential.

Superoxide radicals are highly reactive and can initiate pathological oxidative metabolism, leading to the oxidation of macromolecules such as DNA, lipids, and proteins. The nervous system contains antioxidant enzymes, including SOD and GPx, that are expressed in higher quantities than CAT (Shivakumar et al., 1991). This spectrum of enzymatic defenses suggests that the brain may efficiently metabolize superoxide, but may have difficulty in eliminating the hydrogen peroxide produced by this reaction (i.e., superoxide dismutation). Hydrogen peroxide accumulation is of major concern, as the brain contains large quantities of iron and copper, which may catalyze the formation of hydroxyl radicals that can induce lipid peroxidation (Oubidar et al., 1996). Enhanced hydrogen peroxide, in turn, is reduced to water by peroxidases, mostly GPx (and Prx) in the brain. GPx levels in neuronal tissue appear to be relatively low for the prevention of peroxide insults. Furthermore, the neuronal cell membrane contains high levels of polyunsaturated fatty acids (Benatti et al., 2004).

Thus, brain cells may be extremely susceptible to peroxidative damage, reflecting the critical role of homeostasis with respect to antioxidant vs. peroxidative stress in the epileptogenesis.

\subsection{Mitochondrial dysfunction}

The brain is particularly susceptible to oxidative damage due to its high aerobic metabolic demand and high iron load (Halliwell, 1992). The brain is rich in mitochondria, the principal source of cellular superoxide $\left(\mathrm{O}_{2}^{-}\right)$formed during respiration (Turrens et al., 1982). It is plausible that prolonged seizures result in sufficient $\mathrm{O}_{2}{ }^{-}$production to overwhelm the endogenous mitochondrial antioxidant defenses by a cascade of events initiated by increased neuronal firing, excessive glutamate release, N-methyl-D-aspartate (NMDA) receptor activation, cytosolic and mitochondrial calcium influx, and increased ATP consumption.

Liang et al. (2000) demonstrated that KA-induced seizures selectively inactivate mitochondrial aconidase (inactivation of endogenous aconidase is a marker of $\mathrm{O}_{2}{ }^{-}$ production) in the rat hippocampus. Maximal inactivation of mitochondrial aconidase occurs in the vulnerable CA3 area of the hippocampus at times preceding overt neuronal death. KA-induced mitochondrial aconidase inactivation and hippocampal neuronal loss were attenuated in transgenic mice overexpressing MnSOD, suggesting a role of mitochondrial superoxide-induced hippocampal damage in experimentally induced seizures (Patel et al., 2001; Patel, 2004; Liang and Patel, 2006; Waldbaum and Patel, 2010).

The role of mitochondrial dysfunction arising from mitochondrial DNA mutation/depletion has been shown to be the cause of certain types of epilepsy. Epileptic seizures are a common phenotype of the inherited mitochondrial disease myoclonic epilepsy with ragged-red fibers, the first epilepsy in which a molecular defect was identified and linked with the epilepsy syndrome (Wallace et al., 1988). One possibility is that mitochondrial free radical generation and resultant dysfunction may contribute to the epileptic seizures associated with mitochondrial diseases. Growing evidence suggests that defects in oxidative phosphorylation complexes can result in increased $\cdot \mathrm{O}_{2}{ }^{-}$production. Seizure activity can be 
induced by paradigms that increase the mitochondrial free radical load, such as local infusion of reductive iron salts (Willmore et al., 1978) or mitochondrial toxins (Zuchora et al., 2001) and age-related neuronal disorders (Waterhouse and DeLorenzo, 2001). Further, synaptic NMDA receptor activation, which results in increased $\cdot \mathrm{O}_{2}{ }^{-}$production, is a necessary factor for seizure generation. For example, overproduction of mitochondrial $\cdot \mathrm{O}_{2}{ }^{-}$ resulted in seizure activity in Mn-SOD (-/-) mice. Mn-SOD (-/-) mice have a severe mitochondrial disease and behavioral manifestations including seizures (Melov et al., 1999). Seizure severity in Mn-SOD (+/-) mice correlated with mitochondrial aconitase inactivation with advancing age (Liang and Patel, 2004).

Recently, we demonstrated that KA-induced increased seizure susceptibility is associated with mitochondrial oxidative stress in the hippocampus (increased mitochondrial lipid peroxidation and protein oxidation and mitochondrial loss of glutathione homeostasis), that KA-induced mitochondrial dysfunction is attributable to decreased Mn-SOD protein expression, mitochondrial membrane potential, and uncoupling protein (UCP)-2 mRNA expression, and that KA-induced activation of caspase- 3 triggered by cytochrome $\mathrm{c}$ release potentiates neuronal degeneration (Shin et al., 2008a). These findings may indicate that endogenous mitochondrial anti-oxidant systems do not respond rapidly enough to oxidative stress.

Mitochondrial uncoupling protein 2 (UCP-2) is expressed in selective regions of the brain (Bechmann et al., 2002). This is the only one of three closely related physiological uncouplers (UCP-1, -2, -3) that is expressed in many regions of the central nervous system (Richard et al., 1998). Failure of inner and outer membrane integrity and the collapse of membrane potentials in mitochondria are among the first critical steps in initiating neuronal cell death (Nicholls and Ward, 2000). UCP-2, by stabilizing mitochondrial membrane potential, may help to reduce the likelihood of cell death. We demonstrated that UCP-2 activation may protect neurons in degenerative processes associated with mitochondrial oxidative stress and changes in transmembrane potential, such as those occurring during seizures, and that UCP-2 may be neuroprotective in the brain, as a negative correction between activation of an apoptotic signal, caspase-3, and UCP-2 expression levels occurs in the hippocampus after KA insult (Shin et al., 2008a). Our findings were consistent with the resistance of UCP-2 transgenic mice to KA-induced seizures (Diano et al., 2003), suggesting that increased UCP-2 expression protects hippocampal neurons against KA insult. Thus, we hypothesize that UCP-2 induction may be a general defense mechanism in neurodegenerative processes, at least in part in epileptogenesis.

\subsection{Redox-active metals}

The involvement of iron in KA injury pathogenesis has been demonstrated. For example, microgliosis and neuronal loss in the hippocampus are reduced in KA-treated rats fed an iron-deficient diet (Shoham and Youdim, 2004). Other findings suggest that increased amounts of both ferric and ferrous forms of iron are involved in the degenerating hippocampus after KA lesion (Ong et al., 1999; Wang et al., 2002), indicating that increased iron in the hippocampus could be a source of free radicals after the initial excitotoxic insult caused by KA. A previous investigation suggested that a KA-induced increase in $\mathrm{Fe}^{2+}$ promoted free radical-evoked damage in the hippocampus (Wang et al., 2002). Furthermore, KA-induced upregulation of iron regulatory proteins and divalent metal transporter-1 isoforms in the rat hippocampus could increase iron influx into neurons and may contribute to neuronal damage (Huang et al., 2006). Because the increase in iron in the CNS may result in increased oxidative stress caused by the reaction of ferrous iron with oxygen and endogenously produced peroxides, maintaining stable iron homeostasis in the brain by ceruloplasmin may be an important factor in protecting the CNS from iron-mediated free radical injury (Patel et al., 2002). 
It has been approximately one century since the addition of selenium (Se) to the periodic table of elements. Since1973, when Rotruck et al. revealed the role of Se in the detoxifying enzyme GPx, this element has been shown to have a positive biological function in various aspects of human health (Rotruck et al., 1973; Rayman, 2000). Research in the past three decades has revealed that Se provides protection from ROS-induced cell damage (Schweizer et al., 2004).

Weber et al. (1991) showed in their case report that plasma Se and blood GPx activity were significantly reduced in children with intractable seizures. Ramaekers et al. (1994) showed in similar cases that seizures could be controlled when the children received supplemental Se.

A link between seizures and Se was suggested from a case report of two children with severe neurodevelopmental regression and intractable seizures who were found to be systematically Se deficient. Oral substitution with Se supplements resulted in reduction of seizures. More importantly, upon Se withdrawal, the seizures returned and could only be controlled by renewed Se supplementation (Ramaekers et al., 1994). Another link between seizures and Se was also suggested from observations of patients on total parenteral nutrition who were at risk of developing seizures until Se was incorporated into the formulations (Brown et al., 1986).

In a model of $\mathrm{Fe}^{2+}$-induced epileptic discharge, Se application normalized the electroencephalographic pattern and reduced cerebral damage (Willmore and Rubin, 1981). Another positive finding showed that blood-brain barrier breakdown in pentylentetrazoleinduced seizures was attenuated by dietary Se administration (Oztas et al., 2001). Similarly, Se-deficient rats were more susceptible to KA-induced excitotoxicity and showed a higher seizure rate when compared with controls on a Se-adequate diet (Savaskan et al., 2003).

\subsection{Arachidonic acid pathway}

Arachidonic acid released from membrane phospholipids during seizures (Bazan et al., 1986) is implicated in epilepsy. Seizures activated cytosolic phopholipase $\mathrm{A}_{2}$ (Visioli et al., 1994) and induced cytosolic phopholipase $A_{2}$ expression (Kajiwara et al., 1996).

Spontaneous seizures in gerbils were associated with increases in prostaglandin $(\mathrm{PG}) \mathrm{D}_{2}$ concentrations in the cerebral cortex, hippocampus, and striatum and the presence of a leukotriene (LT)C 4 -like substance in the cortex (Leifke et al., 1994). These areas participate in seizure generation and propagation. The formation of immunoreactive PGF $_{2 a}$ and LT-like activity has been detected in the brains of spontaneously convulsing gerbils (Simmet et al., 1988). PGs and hydroxyeicosatetraenoic acids were present in the rat brain following bicuculine-induced seizures (Birkle and Bazan, 1987), indicating the stimulation of both cyclooxygenase (COX) and lipoxygenase (LOX) activity.

In another seizure model, the genetically epilepsy-susceptible E1 mouse, COX-2 expression in the hippocampus was upregulated after epileptic seizures, and indomethacin, a COX inhibitor, shortened the duration from seizure onset to full recovery (Okada et al., 2001).

Rofecoxib, a COX-2 inhibitor, significantly reduced KA-induced cell death in the rat hippocampus (Kunz and Oliw, 2001a). Cerecoxib, another COX-2 inhibitor, was effective in reducing electroshock-induced convulsions in rats (Shafiq et al., 2003). However, nimesulide, one of the COX-2 inhibitors, aggravated KA-induced seizures in rats (Kunz and Oliw, 2001b). Furthermore, as an earlier report indicated that indomethacin potentiates the neurotoxic action of KA (Baran et al., 1994), reduction in a certain type of PGs may be assumed to potentiate the KA action. Similarly, neither aspirin, a COX inhibitor, nor 
NS-398, a COX-2 inhibitor, alone protected against KA-induced neurotoxicity in our earlier findings (Kim et al., 1998; Kim et al., 2000a).

The KA-induced toxic behavioral signs, oxidative stress (lipid peroxidation and protein oxidation), impairment of GSH status, and the loss of hippocampal neurons were dosedependently attenuated by phenidone, a dual inhibitor of COX/LOX pathways, NS-398 plus esculetin, an inhibitor of LOX, or aspirin plus esculetin. In addition, we demonstrated that phenidone attenuates neurotoxicity in vitro when induced by KA or ischemic conditions via antioxidant action (Wie et al., 1999). Thus, it is possible that both COX and LOX pathways are required to trigger the KA syndrome. However, the precise role of the arachidonic acid pathway in epileptogenesis requires further exploration.

\subsection{Aging and susceptibility to oxidative stress}

Seizure incidence in the elderly is higher when compared with younger populations; in patients over the age of 75, it increases by up to two- to three-fold (Ramsay et al., 2004). Furthermore, elderly patients with epilepsy most often present with complex partial seizures that have a higher recurrence rate than those in the younger population (Jetter and Cavazos, 2008). Therefore, knowledge about the susceptibility of the brain to seizure disorders in ageing is of critical importance in geriatric medicine and public health. At present, the mechanisms responsible for age-dependent regulation of seizure-induced cell damage remain unclear. However, many laboratories have demonstrated that the cellular steady-level of oxidative damage increases with age in all species examined to date (Barja, 2000). The increase is especially pronounced in the latter part of the lifespan, resulting in increased susceptibility to excitatory stimuli (Kim et al., 2002; Shin et al., 2008a and 2008b).

A few studies in neonatal and adult rats explore age-related cerebral vulnerability in response to seizure insults (Sullivan et al., 2003; Nitecka et al., 1984). In addition, seizureinduced oxidative stress is highly age dependent (Sullivan et al., 2003; Shin et al., 2008b).

Increased oxygen tension (Hauser and Annegers, 1991) and local infusion of redox-active iron salts (Willmore et al., 1978) or mitochondrial toxins (Zuchora et al., 2001) were able to increase mitochondrial free radicals and induce seizure activity. The finding that the 8-

OHdG level is pronounced in aging rats is proof of oxidative DNA adduct accumulation in aged rats.

We previously suggested that seizure-mediated oxidative modification is more pronounced in the hippocampus during aging (Shin et al., 2008a). KA-induced increased seizure susceptibility is associated with mitochondrial oxidative stress in the hippocampus. In addition, KA-induced mitochondrial dysfunction is attributable to decreased Mn-SOD protein expression, mitochondrial transmembrane potential, and UCP-2 mRNA expression, which leads to activation of caspase- 3 triggered by cytochrome $\mathrm{c}$ release and potentiates neuronal degeneration. All of the KA responses were more pronounced in aging animals than in young animals. In contrast, endogenous free radical scavenging enzymes did not exhibit rapid adaptation in response to increased oxygen radical formation (Kim et al., 2000b; Bruce and Baudry, 1995), especially in aging animals. Therefore, age-related increases in susceptibility to the neurotoxic effects of seizure induction and seizure-induced injury are associated with vulnerability to oxidative stress in an age-dependent manner.

An animal model with senescence characteristics would provide a useful tool for assessing contributions to increased susceptibility to excitatory insult with age. A senescenceaccelerated mouse (SAM) has been developed by Takeda et al. (Takeda et al., 1994) as a model of accelerated aging. The senescence-resistant mouse (SAM-R) ages normally, 
whereas the senescence-accelerated-prone mouse (SAM-P) has a shortened lifespan and early manifestations of various signs of senescence.

Several studies have compared brain mitochondria isolated from SAM-P mice with those isolated from SAM-R mice and have demonstrated that aged animals may be more susceptible to the excitotoxic action of activated KA receptors (Wozniak et al., 1991). Moreover, KA-induced seizures and oxidative damage were more pronounced in SAM-P8 than SAM-R1 mice (Kim et al., 2002; Shin et al., 2008a). KA-induced seizure susceptibility in SAM-P8 mice paralleled prominent increases in lipid peroxidation and protein oxidation and was accompanied by significant impairment in glutathione homeostasis in the hippocampus. These findings were more pronounced in the mitochondrial fraction than in the hippocampal homogenate. Consistently, KA-induced decreases in mitochondrial MnSOD protein expression, mitochondrial transmembrane potential, and UCP-2 expression were more prominent in SAM-P8 than in SAM-R1 mice. Marked cytochrome c release from mitochondria into the cytosol and a higher level of caspase-3 cleavage were observed in KA-treated SAM-P8 mice. Additionally, electron microscopic evaluation indicates that KAinduced increases in mitochondrial damage and lipofuscin-like substances were more pronounced in SAM-P8 than SAM-R1 animals (refer to Fig. 2). These results suggest that KA-induced oxidative stress contributes to hippocampal degeneration in the senility-prone organism.

\section{Antioxidant strategy for seizure}

\subsection{Endogenous antioxidants}

As clinical and experimental evidence has demonstrated that oxidative stress is involved in the pathogenesis of epileptic seizures, many laboratories have evaluated the therapeutic potential of various antioxidants for the treatment of epilepsy. The most extensively studied endogenous antioxidant in animal models of epilepsy is melatonin. Melatonin is a pineal gland hormone and well-known free radical scavenger whose basal level decreases in the saliva of epileptic patients (Ardura et al., 2010). Anti-convulsive and antioxidant effects of melatonin have been demonstrated in various animal models of epilepsy. Melatonin attenuated seizure activity and neurodegenerative changes induced by KA (Yamamoto and Mohanan, 2003), PTZ (Solmaz et al., 2009), or pilocarpine (Costa-Lotufo et al., 2002). In addition, pinealectomy-induced melatonin deficiency enhanced neurodegenerative damage evoked by KA (Manev et al., 1996). Suppression of ROS and RNS production (Giusti et al., 1996), blockade of lipid peroxidation and nucleic oxidation (Yamamoto and Mohanan, 2003), and maintenance of glutathione homeostasis and the glutathione-related antioxidant enzyme system (Floreani et al., 1997; Chen and Chuang, 1999) mediated by melatonin were shown to be important for anti-convulsive and neuroprotective effects.

Lipoic acid is an endogenous thiol and a cofactor for a-ketodehydrogenase complexes that is present in very small amounts in mammalian tissues (Packer, 1994). As lipoic acid does not exist in free form, but is bound to an enzyme complex, endogenous lipoic acid may be unavailable as an antioxidant (Packer, 1994). However, dietary intake of free unbound lipoic acid produces strong antioxidant effects in vivo and in vitro (Packer et al., 1995).

Dihydrolipoic acid, a reduced form of lipoic acid in cells, is a more potent antioxidant than lipoic acid. Lipoic acid and dihydrolipoic acid exert antioxidant effect by ROS quenching, transient metal chelating, and by increasing the antioxidant efficiency of a-tocopherol and ascorbate (Packer et al., 1995). In other words, dihydrolipoic acid regenerates ascorbate from dehydroascorbate, and then ascorbate restores a-tocopherol from its free radical form. Recently, de Freitas and colleagues demonstrated anti-convulsive effects of lipoic acid in pilocarpine-treated rats (Militão et al., 2010; de Freitas, 2010). In their study, lipoic acid inhibited seizure activity and oxidative damage induced by pilocarpine via inhibition of lipid 
peroxidation and nitrite formation, and enhancement of antioxidant enzyme activities (Militão et al., 2010). Moreover, lipoic acid abolished pilocarpine-induced changes in $\mathrm{Na}^{+}$, $\mathrm{K}^{+}$-ATPase activity (de Freitas, 2010). $\mathrm{Na}^{+}, \mathrm{K}^{+}$-ATPase is a key enzyme in brain excitability and it is sensitive to the redox state of the regulatory sufhydryl group (Lima et al., 2008). Thus, it was suggested that lipoic acid modulates neuronal excitability and the appearance or propagation of certain types of seizures through its antioxidant capacity.

\subsection{Dietary and herbal antioxidants}

Many studies have indicated that ascorbate ameliorates convulsive behavior and neuronal death induced by pilocarpine (Santos et al., 2008), KA (MacGregor et al., 1996), PTZ (Schneider Oliveira et al., 2004), and TMT (Shin et al., 2005). Ascorbate-mediated anticonvulsive and neuroprotective effects can be achieved by restoring the endogenous antioxidant system as well as by direct scavenging of free radicals. Shin et al. (2005) reported that ascorbate attenuates TMT-induced convulsive behavior and consequent neuronal damage via inhibition of initial oxidative stress and maintenance of glutathione homeostasis. In addition, ascorbate enhances CAT activity in the rat hippocampus after pilocarpine treatment (Santos et al., 2008). However, several in vitro and in vivo studies have indicated pro-oxidant effects of ascorbate when the brain iron level was elevated (Sadrzadeh and Eaton, 1988). Thus, the effects of ascorbate on chronic consequences following epileptic seizure remain to be clarified.

a-tocopherol, a lipophilic antioxidant, is able to penetrate the BBB and accumulate at high concentration in the brain (Veinbergs et al., 2000). Evidence indicates that the plasma level of a-tocopherol is significantly lower in epileptic patients than in controls (Sudha et al., 2001), implying that a-tocopherol supplementation can be helpful in suppressing seizures and neuronal damage. In animal studies, however, a-tocopherol's anticonvulsant potential is controversial. Treatments with a-tocopherol have had beneficial effects on seizure activity and neurodegeneration induced by PTZ (Kalayci et al., 2002) or pilocarpine (Tomé et al., 2010). a-tocopherol attenuated lipid peroxidation and nitrite formation, and it increased SOD and CAT activity after pilocarpine-induced seizure (Tomé et al., 2010). In particular, a-tocopherol reduced BBB disruption after PTZ-induced epileptic seizure via lipid peroxidation inhibition and adhesion molecule expression (Kalayci et al., 2002). In contrast, a-tocopherol failed to attenuate seizure activity induced by KA (Levy et al., 1992; Kim et al., 1997) or amygdala kindling (Levy et al., 1992). Thus, the precise pharmacological mechanism of a-tocopherol in response to diverse seizures remains elusive.

Polyphenolics, the group of antioxidants containing a polyphenolic substructure, include flavonoid and non-flavonoid polyphenolics. One of the most-studied polyphenolics in epilepsy models is curcumin. Curcumin is the active antioxidant ingredient of Curcuma longa, a prime component of curry powder. Curcumin attenuates KA-induced seizure, oxidative stress, and consequent neuronal death (Shin et al., 2007). Curcumin produces neuroprotective effects by maintaining glutathione levels and inhibiting lipid peroxidation. Other than these direct antioxidant properties, curcumin increases heme oxygenase-1 expression, an inducible antioxidant defense enzyme, in astrocytes and endothelial cells (Scapagnini et al., 2002). Moreover, it has been suggested that curcumin decreases the expression of cyclooxygenase and lipoxygenase at the transcriptional and post-translational levels (Rao, 2007; Hong et al., 2004). The recently developed curcumin manganese complex has more potent anti-convulsive and neuroprotective effects than curcumin in the KA model through SOD-like activity, NO scavenging activity, and suppression of neuronal injury markers (Sumanont et al., 2006).

Anti-convulsive effects of ginsenosides, the terpenoid saponins from Panax ginseng, have been extensively studied in epileptic models in vitro (Kim and Rhim, 2004) and in vivo 
(Shin et al., 2009b and 2009c; Lian et al., 2006). Ginsenosides have been shown to attenuate seizure activity induced by KA (Shin et al., 2009b and 2009c; Lian et al., 2006), pilocarpine (Lian et al., 2006), or PTZ (Lian et al., 2006), and to inhibit NMDA-mediated epileptic discharge in vitro (Kim and Rhim, 2004). Shin et al. (2009b) demonstrated that KA-induced mitochondrial dysfunction (as revealed by decreased mitochondrial membrane potential) and impaired mitochondrial antioxidant capacity (as revealed by decreased SOD-2 expression and GSH/GSSG ratio in the mitochondrial fraction) were significantly blocked by ginsenosides. In addition, ultrastructural mitochondrial damage and mitochondrial oxidative stress induced by KA are also attenuated by ginsenosides. Considering the suggested key role of mitochondrial dysfunction in the oxidative stress associated with epileptic seizure (Waldbaum and Patel, 2010), preservation of mitochondrial integrity and membrane potential may be the main factor of antioxidant activity mediated by ginsenosides. Moreover, ginsenosides also inhibit KA-induced synaptosomal oxidative stress and presynaptic ultrastructural damage via adenosine $\mathrm{A}_{2 \mathrm{~A}}$ receptor activation (Shin et al., 2009c), suggesting wide-ranging antioxidant potential with neuroprotection mediated by ginsenosides.

Honeybee propolis, which is composed of caffeic acid phenethyl ester and various flavonoids, attenuated seizure activity and neuronal damage induced by KA through maintenance of glutathione homeostasis and adenosine $\mathrm{A}_{1}$ receptor activation (Kwon et al., 2004). A standard extract of Ginkgo biloba leaves, EGb 761 consisting of flavonoids and terpene lactones also showed seizure suppressing effects in response to PTZ (Ilhan et al., 2006), and EGb 761 neuroprotection was correlated with its antioxidant effects (Ilhan et al., 2006).

\subsection{Therapeutic intervention with novel antioxidants}

Much evidence supports the idea that oxidative stress is involved in the pathogenesis of epilepsy and that antioxidants or radical scavengers ameliorate seizure activity and neuronal damage in various epileptic models. Hence, newly synthesized agents with antioxidant properties can be expected to have therapeutic potential against epilepsy.

Neither the salen SOD mimetic (EUK-134) nor the metalloporphyrin SOD mimetic (MnTBAP) affected seizure latency and duration induced by KA (Rong et al., 1999; Liang et al., 2000). However, these agents blocked KA-induced neuronal death, lipid peroxidation, nitrite formation, and nucleic acid oxidation in vivo (Rong et al., 1999; Liang et al., 2000) and in vitro (Liu et al., 2001). Rong et al. (1999) suggested that EUK-134-mediated inhibition of AP-1 and NF- $\mathrm{kB}$ DNA-binding activity, oxidative stress-sensitive transcription factors, is important in protection of KA-induced neurotoxicity. Another SOD mimetic (Tempol) also protects neuronal cells via inhibition of apoptotic changes and formation of superoxide and nitrite after intrahippocampal microinjection of KA. Seizure-like hippocampal electroencephalographic activity was not affected by Tempol in this model (Chuang et al., 2009). Therefore, it is still questionable whether these enzymatic antioxidant mimetics are valuable therapeutic agents for epilepsy in terms of seizure suppression.

A GPx mimic, aspalatone, inhibited seizure, oxidative stress, and consequent hippocampal neuronal death induced by KA (Kim et al., 1997). Aspalatone, a compound derived from aspirin and maltol, directly scavenged hydroxyl radicals, but not superoxide radicals, in an in vitro ESR study (Choi et al., 1995). Additionally, aspalatone enhanced anti-peroxidative enzyme activity, such as GPx and CAT, in rat blood (Kim et al., 1996). It was suggested that the maltol moiety contributes to the antioxidant effect of aspalatone (Han et al., 1994), but the hydroxyl radical scavenging capacity of aspalatone is more potent than that of maltol (Choi et al., 1995). Moreover, maltol did not increase CAT activity and it increased GPx activity to a lesser extent than aspalatone (Kim et al., 1996). Hence, some other functional 
units, as well as the maltol moiety in the structure, may be involved in the antioxidant effects of aspalatone. In this respect, it was suggested that metabolism to salicylmaltol is a prerequisite for antioxidant capacity of aspalatone, because salicylmaltol, a major metabolite of aspalatone, is more efficient in hydroxyl radical quenching and enhancing antioxidant enzyme activity than aspalatone (Kim et al., 1996; Choi et al., 1995).

\subsection{Application of antioxidants for adjunctive antiepileptic therapy}

Accumulating evidence (Hamed et al., 2004; Yüksel et al., 2000; Schulpis et al., 2006; Varoglu et al., 2010; Liu et al., 1998) suggests that antiepileptic drugs induce or exacerbate oxidative injury in epileptic patients. Several first-choice drugs for various epileptic syndromes, such as valproic acid, cabamazepine, phenytoin, or phenobarbital, increase lipid peroxidation and nucleic acid oxidation in blood or blood cells (Hamed et al., 2004; Yüksel et al., 2000; Schulpis et al., 2006; Varoglu et al., 2010; Liu et al., 1998). In addition, the antioxidant defense system is also altered by these antiepileptic drugs. For example, SOD activity is increased (Yüksel et al., 2000), decreased (Niketić et al., 1995), or unaffected (Verrotti et al., 2002) by valproic acid treatment. These discrepancies in antioxidant enzyme activity may be due to differences in the subjects (i.e., adult, adolescent, or child), medication duration (i.e., long-term or short-term), or material analyzed (i.e., plasma, serum or erythrocytes). As another example, Sobaniec et al. (2006) showed elevation in GR activity in children treated with valproic acid, whereas Graf et al. (1998) reported a reduction in GR activity only in children with a severe adverse experience related to valproic acid therapy.

Cabamazepine has been shown to induce disturbances in enzymatic antioxidant status and lipid peroxidation to a lesser extent than valproic acid (Yüksel et al., 2000; Sobaniec et al., 2006; Hamed et al., 2004) or phenytoin (Liu et al., 1998). One possible mechanism related to oxidative stress induced by antiepileptic drugs is that these drugs metabolize to reactive epoxide intermediates, which can covalently bind to biomolecules and then induce structural and functional impairments (Lindhout et al., 1984). Antiepileptic drug-induced changes in antioxidant system markers and oxidative stress in epileptic patient blood are summarized in Table 1.

Based on the beneficial effects of antioxidants in animal models of epileptic seizure, several antioxidants have been applied to epileptic patients as an adjunctive antiepileptic therapy with partial success. After treatment with $\mathrm{N}$-acetylcysteine, a glutathione precursor, as an adjunctive agent, myoclonus was markedly improved and occurrence of generalized seizure decreased in several case reports with progressive myoclonic epilepsy (Ben-Menachem et al., 2000; Edwards et al., 2002). In addition, serum glutathione levels gradually increased during $\mathrm{N}$-acetylcysteine treatment (Edwards et al., 2002), supporting previous experimental findings (Shin et al., 2005 and 2008b) suggesting that impaired homeostasis in glutathione and the glutathione-related antioxidant enzyme system are important pathological factors connected with epilepsy. However, the pharmacological effect of $\mathrm{N}$-acetylcysteine is doubtful in other types of epilepsy (Ben-Menachem et al., 2008), and some side effects, such as sensorineural deafness and epigastric pain, developed after treatment with $\mathrm{N}$ acetylcysteine (Edwards et al., 2002). Thus, comprehensive and controlled clinical trials are required to confirm the pharmacological effects of $\mathrm{N}$-acetylcysteine in humans.

Gupta and colleagues have reported the beneficial effects of melatonin as an add-on therapy for epileptic children in a series of clinical trials (Gupta et al., 2004a, 2004b, 2004c, and 2005). According to this research group, add-on treatment with melatonin elevated GR and GPx activity in the blood of epileptic children receiving valproic acid or carbamazepine monotherapy (Gupta et al., 2004b and 2004c). The clinical trials of Gupta and colleagues showed that add-on treatment with melatonin improved sleep patterns, behavior, attention, 
cognition, and memory function in epileptic children receiving valproic acid monotherapy (Gupta et al. 2004a and 2005), which may reflect neuroprotection provided by melatonin. On the other hand, clinical trials have yielded conflicting results for the effect of atocopherol as an adjunctive antiepileptic agent. Ogunmekan and Hwang (1989) reported that a-tocopherol supplementation significantly reduced seizures; however, Raju et al. (1994) did not show any significant difference between a-tocopherol and placebo. Although both trials were done in refractory epileptic patients, Ogunmekan and Hwang (1989) enrolled child patients, whereas Raju et al. (1994) enrolled adult patients. Moreover, the duration of a-tocopherol supplementation was limited to 3 months (Raju et al., 1994), which may be too short for precise evaluation of the effect of a-tocopherol. Thus, the effects of a-tocopherol must be examined for a longer time period.

Some antiepileptic drugs, such as zonisamide and topiramate, have showed antioxidant effects under experimental conditions. Zonisamide directly scavenged hydroxyl radicals and NO in an in vitro ESR study (Mori et al., 1998). Zonisamide also significantly inhibited KAinduced free radical formation (Ueda et al., 2005) and iron-induced 8-OHdG formation (Komatsu et al., 2000) in vivo. Another antiepileptic drug, topiramate, inhibited lipid peroxidation and NO formation, and decreased glutathione and GPx activity in the brain and blood after PTZ-induced seizure (Naziroğlu et al., 2009; Kutluhan et al., 2009). Moreover, several clinical trials have indicated a successful therapeutic outcome of zonisamide and topiramate as monotherapies (Glauser and Pellock, 2002; Wheless et al., 2004) or adjunctive treatments (Faught et al., 2001; Elterman et al., 1999) in epileptic patients.

\section{Conclusion}

This review provides an overview of oxidative stress and antioxidant defense in various seizure models. Findings vary, but an impaired antioxidant system, mitochondrial dysfunction, redox-active metals, arachidonic acid pathway activation, and aging may be critical factors for epileptogenesis. Therapeutic intervention with antioxidant components and adjunctive antiepileptic therapy using antioxidants may be beneficial strategies for minimizing neurodegeneration in susceptible neuronal targets of the SE. However, further studies are required to understand specific molecular/cellular mechanisms associated with oxidative stress or impaired antioxidant systems in various epileptic seizure models.

\section{Acknowledgments}

This study was supported by a grant (\#2010K000812) from the Brain Research Center from $21^{\text {st }}$ Century Frontier Research Program funded by the Ministry of Science and Technology, Republic of Korea. Jae-Hyung Bach was supported by BK 21 program.

\section{References}

Ali SF, LeBel CP, Bondy SC. Reactive oxygen species formation as a biomarker of methylmercury and trimethyltin neurotoxicity. Neurotoxicology. 1992; 13:637-648. [PubMed: 1475065]

Ardura J, Andres J, Garmendia JR, Ardura F. Melatonin in epilepsy and febrile seizures. J. Child Neurol. 2010; 25:888-891. [PubMed: 20505155]

Arrigo AP. Gene expression and the thiol redox state. Free Radic Biol Med. 1999; 27:936-944. [PubMed: 10569626]

Ashrafi MR, Shams S, Nouri M, Mohseni M, Shabanian R, Yekaninejad MS, Chegini N, Khodadad A, Safaralizadeh R. A probable causative factor for an old problem: selenium and glutathione peroxidase appear to play important roles in epilepsy pathogenesis. Epilepsia. 2007; 48:1750-1755. [PubMed: 17555528]

Aycicek A, Iscan A. The effects of carbamazepine, valproic acid and phenobarbital on the oxidative and antioxidative balance in epileptic children. Eur. Neurol. 2007; 57:65-69. [PubMed: 17179706] 
Baran H, Vass K, Lassmann H, Hornykieewicz O. The cyclooxygenase and lipoxygenase inhibitor BW755C protects rats against kainic acid-induced seizures and neurotoxicity. Brain Res. 1994; 646:201-206. [PubMed: 8069664]

Barja G. The flux of free radical attack through mitochondrial DNA is related to aging rate. Aging (Milano). 2000; 12:342-355. [PubMed: 11126520]

Bashkatova V, Narkevich V, Vitskova G, Vanin A. The influence of anticonvulsant and antioxidant drugs on nitric oxide level and lipid peroxidation in the rat brain during penthylenetetrazole-induced epileptiform model seizures. Prog. Neuropsychopharmacol. Biol. Psychiatry. 2003; 27:487-492. [PubMed: 12691785]

Bazan NG, Birkle DL, Tang W, Reddy TS. The accumulation of free arachidonic acid, diaglycerol, prostaglandins, and lipoxygenase reaction products in the brain during experimental epilepsy. Adv. Neurol. 1986; 44:879-902. [PubMed: 3010683]

Bechmann I, Diano S, Warden CH, Bartfai T, Nitsch R, Horvath TL. Brain mitochondrial uncoupling protein 2(UCP2): a protective stress signal in neuronal injury. Biochem Pharmacol. 2002; 64:363367. [PubMed: 12147286]

Beit-Yannai E, Kohen R, Horowitz M, Trembovler V, Shohami E. Changes of biological reducing activity in rat brain following closed head injury: A cyclic voltammetry study in normal and heatacclimated rats. J. Cereb. Blood Flow \& Metab. 1997; 17:273-279. [PubMed: 9119900]

Bellissimo MI, Amado D, Abdalla DS, Ferreira EC, Cavalheiro EA, Naffah-Mazzacoratti MG. Superoxide dismutase, glutathione peroxidase activities and the hydroperoxide concentration are modified in the hippocampus of epileptic rats. Epilepsy Res. 2001; 46:121-128. [PubMed: 11463513]

Ben-Ari Y. Limbic seizure and brain damage produced by kainic acid: mechanisms and relevance to human temporal lobe epilepsy. Neuroscience. 1985; 14:375-403. [PubMed: 2859548]

Ben-Ari Y, Cossart R. Kainate, a double agent that generates seizures: two decades of progress. Trends Neurosci. 2000; 23:580-587. [PubMed: 11074268]

Benatti P, Peluso G, Nicolai R, Calvani M. Polyunsaturated fatty acids: biochemical, nutritional and epigenetic properties. J. Am. Coll. Nutr. 2004; 23:281-302. [PubMed: 15310732]

Ben-Menachem E, Kyllerman M, Marklund S. Superoxide dismutase and glutathione peroxidase function in progressive myoclonus epilepsies. Epilepsy Res. 2000; 40:33-39. [PubMed: 10771256]

Birkle DL, Bazan NG. Effect of bicuculline-induced status epilepticus on prostaglandins and hydroxyeicosatetraenoic acids in rat brain subcellular fractions. J. Neurochem. 1987; 48:17681778. [PubMed: 3106572]

Brown GC, Borutaite V. Nitric oxide, mitochondria, and cell death. IUBMB Life. 2001; 52:189-195. [PubMed: 11798032]

Brown MR, Cohen HJ, Lyons JM, Curtis TW, Thunberg B, Cochran WJ, Klish WJ. Proximal muscle weakness and selenium deficiency associated with long term parenteral nutrition. Am. J. Clin. Nutr. 1986; 43:549-554. [PubMed: 3083669]

Browning RA, Wang C, Lanker ML, Jobe PC. Electroshock- and pentylenetetrazol-induced seizures in genetically epilepsy-prone rats (GEPRs): differences in threshold and pattern. Epilepsy Res. 1990; 6:1-11. [PubMed: 2357951]

Bruce AJ, Baudry M. Oxygen free radicals in rat limbic structures after kainate-induced seizures. Free Radic. Biol. Med. 1995; 18:993-1002. [PubMed: 7628735]

Chen ST, Chuang JI. The antioxidant melatonin reduces cortical neuronal death after intrastriatal injection of kainate in the rat. Exp. Brain Res. 1999; 124:241-247. [PubMed: 9928847]

Choi, JH.; Min, DP.; Han, SH.; Nam, SW.; Choi, DY.; Kim, C.; Koo, CH.; Jhoo, WK.; Kim, HC. Aspalatone as a scavenger of hydroxyl free radical.; The 44th Convention of the Pharmaceutical Society of Korea. 1995. p. 183

Chuang YC, Chen SD, Liou CW, Lin TK, Chang WN, Chan SH, Chang AY. Contribution of nitric oxide, superoxide anion, and peroxynitrite to activation of mitochondrial apoptotic signaling in hippocampal CA3 subfield following experimental temporal lobe status epilepticus. Epilepsia. 2009; 50:731-746. [PubMed: 19178557] 
Costa-Lotufo LV, Fonteles MM, Lima IS, de Oliveira AA, Nascimento VS, de Bruin VM, Viana GS. Attenuating effects of melatonin on pilocarpine-induced seizures in rats. Comp. Biochem. Physiol. C Toxicol. Pharmacol. 2002; 131:521-529. [PubMed: 11976067]

Coyle JT, Puttfarcken P. Oxidative stress, glutamate, and neurodegenerative disorders. Science. 1993; 262:689-695. [PubMed: 7901908]

Diano S, Matthews RT, Patrylo P, Yang L, Beal MF, Barnstable CJ, Horbath TL. Uncoupling protein 2 prevents neuronal death including that occurring during seizures: a mechanism for preconditioning. Endocrinology. 2003; 144:5014-5021. [PubMed: 12960023]

Dailey JW, Reigel CE, Mishra PK, Jobe PC. Neurobiology of seizure predisposition in the genetically epilepsy-prone rat. Epilepsy Res. 1989; 3:3-17. [PubMed: 2563686]

de Freitas RM. Lipoic acid alters delta-aminolevulinic dehydratase, glutathione peroxidase and $\mathrm{Na}+\mathrm{K}$ +-ATPase activities and glutathione-reduced levels in rat hippocampus after pilocarpine-induced seizures. Cell Mol. Neurobiol. 2010; 30:381-387. [PubMed: 19798568]

de Freitas RM, de Sousa FC, Vasconcelos SM, Viana GS, Fonteles MM. [Acute alterations of neurotransmitters levels in striatum of young rat after pilocarpine-induced status epilepticus]. Arq. Neuropsiquiatr. 2003; 61:430-433. [PubMed: 12894279]

Devinsky O. Diagnosis and treatment of temporal lobe epilepsy. Rev. Neurol. Dis. 2004; 1:2-9. [PubMed: 16397445]

Dugan LL, Sensi SL, Canzoniero LM, Handran SD, Rothman SM, Lin TS, Goldberg MP, Choi DW. Mitochondrial production of reactive oxygen species in cortical neurons following exposure to Nmethyl-D-aspartate. J. Neurosci. 1995; 15:6377-6388. [PubMed: 7472402]

Dyer RS, Walsh TJ, Wonderlin WF, Bercegeay M. The trimethyltin syndrome in rats. Neurobehav. Toxicol. Teratol. 1982; 4:127-133. [PubMed: 7201084]

Edwards MJ, Hargreaves IP, Heales SJ, Jones SJ, Ramachandran V, Bhatia KP, Sisodiya S. Nacetylcysteine and Unverricht-Lundborg disease: variable response and possible side effects. Neurology. 2002; 59:1447-1449. [PubMed: 12427904]

Ekonomou A, Angelatou F. Upregulation of NMDA receptors in hippocampus and cortex in the pentylenetetrazol-induced "kindling" model of epilepsy. Neurochem. Res. 1999; 24:1515-1522. [PubMed: 10591400]

Elterman RD, Glauser TA, Wyllie E, Reife R, Wu SC, Pledger G, Topiramate YP Study Group. A double-blind, randomized trial of topiramate as adjunctive therapy for partial-onset seizures in children. Neurology. 1999; 52:1338-1344. [PubMed: 10227615]

Erakovic V, Zupan G, Varljen J, Simonic A. Pentylenetetrazol-induced seizures and kindling: changes in free fatty acids, superoxide dismutase, and glutathione peroxidase activity. Neurochem. Int. 2003; 42:173-178. [PubMed: 12421597]

Faught E, Ayala R, Montouris GG, Leppik IE, Zonisamide 922 Trial Group. Randomized controlled trial of zonisamide for the treatment of refractory partial-onset seizures. Neurology. 2001; 57:1774-1779. [PubMed: 11723262]

Ferriero DM. Protecting neurons. Epilepsia. 2005; 46(Suppl.7):45-51. [PubMed: 16201995]

Floreani M, Skaper SD, Facci L, Lipartiti M, Giusti P. Melatonin maintains glutathione homeostasis in kainic acid-exposed rat brain tissues. FASEB J. 1997; 11:1309-1315. [PubMed: 9409550]

Frantseva MV, Velazquez JL, Hwang PA, Carlen PL. Free radical production correlates with cell death in an in vitro model of epilepsy. Eur. J. Neurosci. 2000; 12:1431-1439. [PubMed: 10762371]

Freitas RM, Sousa FC, Vasconcelos SM, Viana GS, Fonteles MM. Pilocarpine-induced status epilepticus in rats: lipid peroxidation level, nitrite formation, GABAergic and glutamatergic receptor alterations in the hippocampus, striatum and frontal cortex. Pharmacol. Biochem. Behav. 2004; 78:327-332. [PubMed: 15219774]

Freitas RM, Vasconcelos SM, Souza FC, Viana GS, Fonteles MM. Oxidative stress in the hippocampus after pilocarpine-induced status epilepticus in Wistar rats. FEBS J. 2005; 272:13071312. [PubMed: 15752349]

Fujikawa DG, Itabashi HH, Wu A, Shinmei SS. Status epilepticus-induced neuronal loss in human without systemic complications or epilepsy. Epilepsia. 2000; 41:981-991. [PubMed: 10961625]

Gastaut H. Introduction to electroencephalography, a neurophysiological method applied current clinical practice. Mars Med. 1950; 87:403-405. [PubMed: 14842252] 
Ghosh S, Baltimore D. Activation in vivo of NF-kappa B by phosphorylation of its inhibitor I kappa B. Nature. 1990; 344:678-682. [PubMed: 2157987]

Giusti P, Franceschini D, Petrone M, Manev H, Floreani M. In vitro and in vivo protection against kainate-induced excitotoxicity by melatonin. J. Pineal Res. 1996; 20:226-231. [PubMed: 8836957]

Glauser TA, Pellock JM. Tropical Review: Zonisamide in pediatric epilepsy: Review of the Japanese experience. J. Child Neurol. 2002; 17:87-96. [PubMed: 11952083]

Graf WD, Oleinik OE, Glauser TA, Maertens P, Eder DN, Pippenger CE. Altered antioxidant enzyme activities in children with a serious adverse experience related to valproic acid therapy. Neuropediatrics. 1998; 29:195-201. [PubMed: 9762695]

Gupta M, Aneja S, Kohli K. Add-on melatonin improves quality of life in epileptic children on valproate monotherapy: a randomized, double-blind, placebo-controlled trial. Epilepsy Behav. 2004a; 5:316-321. [PubMed: 15145300]

Gupta M, Gupta YK, Agarwal S, Aneja S, Kohli K. A randomized, double-blind, placebo controlled trial of melatonin add-on therapy in epileptic children on valproate monotherapy: effect on glutathione peroxidase and glutathione reductase enzymes. Br. J. Clin. Pharmacol. 2004b; 58:542547. [PubMed: 15521903]

Gupta M, Gupta YK, Agarwal S, Aneja S, Kalaivani M, Kohli K. Effects of add-on melatonin administration on antioxidant enzymes in children with epilepsy taking carbamazepine monotherapy: a randomized, double-blind, placebo-controlled trial. Epilepsia. 2004c; 45:16361639. [PubMed: 15571523]

Gupta M, Aneja S, Kohli K. Add-on melatonin improves sleep behavior in children with epilepsy: randomized, double-blind, placebo-controlled trial. J. Child Neurol. 2005; 20:112-115. [PubMed: 15794175]

Halliwell B. Reactive oxygen species and central nervous system. J. Neurochem. 1992; 59:1609-1623. [PubMed: 1402908]

Halliwell B. Antioxidant defence mechanisms: from the beginning to the end (of the beginning). Free Radic. Res. 1999; 31:261-272. [PubMed: 10517532]

Hamed SA, Abdellah MM, El-Melegy N. Blood levels of trace elements, electrolytes, and oxidative stress/antioxidant systems in epileptic patients. J. Pharmacol. Sci. 2004; 96:465-473. [PubMed: 15599098]

Han BH, Suh DY, Yang HO, Park YH, Kim YC. Synthesis and antiplatelet effects of new antithrombotic agent aspalatone with low ulcerogenicity. Arzneimittelforschung. 1994; 44:11221126. [PubMed: 7818584]

Hauser WA, Annegers JF. Risk factors for epilepsy. Epilepsy Res. Suppl. 1991; 4:45-52. [PubMed: 1815610]

Hong J, Bose M, Ju J, Ryu JH, Chen X, Sang S, Lee MJ, Yang CS. Modulation of arachidonic acid metabolism by curcumin and related beta-diketone derivatives: effects on cytosolic phospholipase A2, cyclooxygenases and 5-lipoxygenase. Carcinogenesis. 2004; 25:1671-1679. [PubMed: 15073046]

Huang RQ, Bell-Horner CL, Dibas MI, Covey DF, Drewe JA, Dillon GH. Pentylenetetrazole-induced inhibition of recombinant gamma-aminobutyric acid type A GABA(A) receptors: mechanism and site of action. J. Pharmacol. Exp. Ther. 2001; 298:986-995. [PubMed: 11504794]

Huang E, Ong WY, Go ML, Connor JR. Upregulation of iron regulatory proteins and divalent metal transporter-1 isoforms in the rat hippocampus after kainate induced neuronal injury. Exp. Brain Res. 2006; 170:376-386. [PubMed: 16328268]

Hussain S, Slikker W Jr. Ali SF. Age-related changes in antioxidant enzymes, superoxide dismutase, catalase, glutathione peroxidase and glutathione in different regions of mouse brain. Int. J. Dev. Neurosci. 1995; 13:811-817. [PubMed: 8770654]

Ilhan A, Iraz M, Kamisli S, Yigitoglu R. Pentylenetetrazol-induced kindling seizure attenuated by Ginkgo biloba extract (EGb 761) in mice. Prog. Neuropsychopharmacol. Biol. Psychiatry. 2006; 30:1504-1510. [PubMed: 16815619]

Imai H, Nishimura T, Sadamatsu M, Liu Y, Kabuto M, Kato N. Type II glucocorticoid receptors are involved in neuronal death and astrocyte activation induced by trimethyltin in the rat hippocampus. Exp. Neurol. 2001; 171:22-28. [PubMed: 11520118] 
Ishida N, Akaike M, Tsutsumi S, Kanai H, Masui A, Sadamatsu M, Kuroda Y, Watanabe Y, McEwen BS, Kato N. Trimethyltin syndrome as a hippocampal degeneration model: temporal changes and neurochemical features of seizure susceptibility and learning impairment. Neuroscience. 1997; 81:1183-1191. [PubMed: 9330376]

Jackson JH. Lectures on the diagnosis of epilepsy. Br. J. Med. 1879; 1:33-36.

Jellinger KA. General aspects of neurodegeneration. J. Neurol. Transm. 2003; 65:101-144.

Jetter GM, Cavazos JE. Epilpsy in the elderly. Semin. Neurol. 2008; 28:336-341. [PubMed: 18777480]

Kajiwara K, Nagawawa H, Shimatsu-Nishikawa S, Ookuri T, Kimura M, Sugaya E. Molecular characterization of seizure-related genes isolated by differential screening. Biochem. Biophys. Res. Commun. 1996; 219:795-799. [PubMed: 8645260]

Kalayci R, Kaya M, Kucuk M, Cimen V, Arican N, Gurses C, Elmas I. Catalase and alpha-tocopherol attenuate blood-brain barrier breakdown in pentylenetetrazole-induced epileptic seizures in acute hyperglycaemic rats. Pharmacol. Res. 2002; 45:129-133. [PubMed: 11846625]

Kim S, Rhim H. Ginsenosides inhibit NMDA receptor-mediated epileptic discharges in cultured hippocampal neurons. Arch. Pharm. Res. 2004; 27:524-530. [PubMed: 15202558]

Kim C, Koo CH, Choi DY, Cho YJ, Choi JH, Im DH, Joo WK, Kim HC. The effect of asplatone, a new antithrombotic agent, on the specific activity of antioxidant enzyme in the rat blood. Arch. Pharm. Res. 1996; 19:348-352.

Kim HC, Choi DY, Jhoo WK, Lee DW, Koo CH, Kim C. Aspalatone, a new antiplatelet agent, attenuates the neurotoxicity induced by kainic acid in the rat. Life Sci. 1997; 61:PL383-PL381.

Kim HC, Suh JH, Won JS, Jhoo WK, Song DK, Kim YH, Wie MB, Suh HW. Phenidone blocks the increases of proenkephalin and prodynorphin gene expression induced by kainic acid in rat hippocampus: involvement of Fos-related antigene protein. Brain Res. 1998; 782:337-342. [PubMed: 9519284]

Kim HC, Jhoo WK, Bing G, Shin EJ, Wie MB, Kim WK, Ko KH. Phenidone prevents kainite-induced neurotoxicity via antioxidant mechanisms. Brain Res. 2000a; 874:15-23. [PubMed: 10936219]

Kim HC, Jhoo WK, Kim WK, Suh JH, Shin EJ, Kato K, Ko KH. An immunocytochemical study of mitochondrial manganese-superoxide dismutase in the rat hippocampus after kainate administration. Neurosci. Lett. 2000b; 281:65-68. [PubMed: 10686417]

Kim HC, Bing G, Jhoo WK, Kim WK, Shin EJ, Park ES, Choi YS, Lee DW, Shin CY, Ryu JR, Ko $\mathrm{KH}$. Oxidative damage causes formation of lipofuscin-like substances in the hippocampus of the senescence-accelerated mouse after kainate treatment. Behav. Brain Res. 2002; 131:211-220. [PubMed: 11844588]

Kitayama T, Ogita K, Nomoto M, Yoneda Y. Sensitization by prolonged glutathione depletion of kainic acid to potentiate DNA binding of the nuclear transcription factor activator protein-1 in murine hippocampus. Neurosci Lett. 1999; 269:157-160. [PubMed: 10454156]

Komatsu M, Hiramatsu M, Willmore LJ. Zonisamide reduces the increase in 8-hydroxy-2'deoxyguanosine levels formed during iron-induced epileptogenesis in the brains or rats. Epilepsia. 2000; 41:1091-1094. [PubMed: 10999546]

Komulainen $\mathrm{H}$, Bondy SC. Increased free intrasynaptosomal Ca2+ by neurotoxic organometals: distinctive mechanisms. Toxicol. Appl. Pharmacol. 1987; 88:77-86. [PubMed: 2436355]

Kontos HA. Oxygen radicals in CNS damage. Chem. Biol. Interact. 1989; 72:229-320. [PubMed: 2557981]

Kovacs R, Schuchmann S, Gabriel S, Kann O, Kardos J, Heinemann U. Free radical-mediated cell damage after experimental status epilepticus in hippocampal slice cultures. J. Neurophysiol. 2002; 88:2909-2918. [PubMed: 12466417]

Kunz T, Oliw EH. The selective cyclooxygenase-2 inhibitor rofecoxib reduces kainate-induced cell death in the rat hippocampus. Eur. J. Neurosci. 2001a; 13:569-575. [PubMed: 11168565]

Kunz T, Oliw EH. Nimesulide aggravates kainic acid-induced seizures in the rat. Pharmacol. Toxicol. 2001b; 88:271-276. [PubMed: 11393589]

Kutluhan S, Naziroğlu M, Celik O, Yilmaz M. Effects of selenium and topiramate on lipid peroxidation and antioxidant vitamin levels in blood of pentylentetrazol-induced epileptic rats. Biol. Trace Elem. Res. 2009; 129:181-189. [PubMed: 19127351] 
Kwan P, Brodie MJ. Early identification of refractory epilepsy. N Eng J Med. 2000; 342:314-319.

Kwon YS, Park DH, Shin EJ, Kwon MS, Ko KH, Kim WK, Jhoo JH, Jhoo WK, Wie MB, Jung BD, Kim HC. Antioxidant propolis attenuates kainate-induced neurotoxicity via adenosine A1 receptor modulation in the rat. Neurosci. Lett. 2004; 355:231-235. [PubMed: 14732473]

Levy SL, Burnham WM, Bishai A, Hwang PA. The anticonvulsant effects of vitamin E: a further evaluation. Can. J. Neurol. Sci. 1992; 19:201-203. [PubMed: 1623446]

Lian XY, Zhang Z, Stringer JL. Anticonvulsant and neuroprotective effects of ginsenosides in rats. Epilepsy Res. 2006; 70:244-256. [PubMed: 16782310]

Liang LP, Patel M. Mitochondrial oxidative stress and increased seizure susceptibility in $\mathrm{Sod} 2^{/+}$mice. Free Radic. Biol. Med. 2004; 36:542-554. [PubMed: 14980699]

Liang LP, Patel M. Seizure-induced changes in mitochondrial redox status. Free Radic. Biol. Med. 2006; 40:316-322. [PubMed: 16413413]

Liang LP, Ho YS, Patel M. Mitochondrial superoxide production in kainate-induced hippocampal damage. Neuroscience. 2000; 101:563-570. [PubMed: 11113305]

Leifke E, Seregi A, Heldt R, Hertting G. In vivo cpmparative study of the seizure- and ischemiainduced synthesis of eicosanoids in the brain of gerbils. Arch Int Pharmacoodyn. Ther. 1994; 328:145-154.

Lima FD, Souza MA, Furian AF, Rambo LM, Ribeiro LR, Martignoni FV, Hoffmann MS, Fighera MR, Royes LF, Oliveira MS, de Mello CF. Na+,K+-ATPase activity impairment after experimental traumatic brain injury: relationship to spatial learning deficits and oxidative stress. Behav. Brain Res. 2008; 193:306-310. [PubMed: 18573545]

Lindhout D, Höppener RJ, Meinardi H. Teratogenicity of antiepileptic drug combinations with special emphasis on epoxidation (of carbamazepine). Epilepsia. 1984; 25:77-83. [PubMed: 6692794]

Liu CS, Wu HM, Kao SH, Wei YH. Serum trace elements, glutathione, copper/zinc superoxide dismutase, and lipid peroxidation in epileptic patients with phenytoin or carbamazepine monotherapy. Clin. Neuropharmacol. 1998; 21:62-64. [PubMed: 9579288]

Liu W, Liu R, Schreiber SS, Baudry M. Role of polyamine metabolism in kainic acid excitotoxicity in organotypic hippocampal slice cultures. J. Neurochem. 2001; 79:976-984. [PubMed: 11739609]

MacGregor DG, Higgins MJ, Jones PA, Maxwell WL, Watson MW, Graham DI, Stone TW. Ascorbate attenuates the systemic kainate-induced neurotoxicity in the rat hippocampus. Brain Res. 1996; 727:133-144. [PubMed: 8842391]

Mahle C, Dasgupta A. Decreased total antioxidant capacity and elevated lipid hydroperoxide concentrations in sera of epileptic patients receiving phenytoin. Life Sci. 1997; 61:437-443. [PubMed: 9244370]

Manev H, Uz T, Kharlamov A, Joo JY. Increased brain damage after stroke or excitotoxic seizures in melatonin-deficient rats. FASEB J. 1996; 10:1546-1551. [PubMed: 8940301]

Mariani E, Polidori MC, Cherubini A, Mecocci P. Oxidative stress in brain aging, neurodegenerative and vascular disease: an overview. J. Chromatogr. B. 2005; 827:65-75.

Melov S, Coskun P, Patel M, Tuinstra R, Miziorko H, Goodman S, Wallace DC. Mitochondrial disease in superoxide dismutase- mutant mice. Proc Natl Acad Sci USA. 1999; 96:845-851.

Migliore L, Fontana I, Colognato R, Coppedè F, Siciliano G, Murri L. Searching for the role and the most suitable biomarkers of oxidative stress in Alzheimer's disease and in other neurodegenerative diseases. Neurobiol. Aging. 2005; 26:587-595. [PubMed: 15708433]

Militão GC, Ferreira PM, de Freitas RM. Effects of lipoic acid on oxidative stress in rat striatum after pilocarpine-induced seizures. Neurochem. Int. 2010; 56:16-20. [PubMed: 19715735]

Millan MH, Wardley-Smith B, Durmuller N, Meldrum BS. The high pressure neurological syndrome in genetically epilepsy prone rats: protective effect of 2-amino-7-phosphono heptanoate. Exp. Neurol. 1991; 112:317-320. [PubMed: 2029931]

Mori A, Noda Y, Packer L. The anticonvulsant zonisamide scavenges free radicals. Epilepsy Res. 1998; 30:153-158. [PubMed: 9600546]

Naziroğlu M, Kutluhan S, Uğuz AC, Celik O, Bal R, Butterworth PJ. Topiramate and vitamin e modulate the electroencephalographic records, brain microsomal and blood antioxidant redox system in pentylentetrazol-induced seizure of rats. J. Membr. Biol. 2009; 229:131-140. [PubMed: 19513780] 
Nicholls DG, Ward MW. Mitochondrial membrane potential and neuronal glutamate excitotoxicity: mortality and millivolts. Trends Neurosci. 2000; 23:166-174. [PubMed: 10717676]

Niketić V, Ristić S, Saicić ZS, Spasić M, Buzadzić B, Stojković M. Activities of antioxidant enzymes and formation of the glutathione adduct of hemoglobin (Hb ASSG) in epileptic patients with long-term antiepileptic therapy. Farmaco. 1995; 50:811-813. [PubMed: 8593178]

Nitecka L, Tremblay E, Charton G, Bouillot JP, Berger ML, Ben-Ari Y. Maturation of kainic acid seizure-brain damage syndrome in the rat. II. Histopathological sequelae. Neuroscience. 1984; 13:1073-1094. [PubMed: 6527790]

Ogita K, Kitayama T, Okuda H, Yoneda Y. Effects of glutathione depletion by 2-cyclohexen-1-one on excitatory amino acids-induced enhancement of activator protein-1 DNA binding in murine hippocampus. J. Neurochem. 2001; 76:1905-1915. [PubMed: 11259509]

Ogunmekan AO, Hwang PA. A randomized, double-blind, placebo-controlled, clinical trial of Dalpha-tocopheryl acetate (vitamin E), as add-on therapy, for epilepsy in children. Epilepsia. 1989; 30:84-89. [PubMed: 2643513]

Okada K, Yuhi T, Tsuji S, Yamashita U. Cyclooxygenase-2 expression in the hippocampus of genetically epilepsy susceptible mice was increased after seizure. Brain Res. 2001; 894:332-335. [PubMed: 11251211]

Ong WY, Ren MQ, Makjanic J, Lim TM, Watt F. A nuclear microscopic study of elemental changes in the rat hippocampus after kainate-induced neuronal injury. J. Neurochem. 1999; 72:15741579. [PubMed: 10098863]

Ong WY, Lu XR, Hu CY, Halliwell B. Distribution of hydroxynonenal-modified proteins in the kainate-leisioned rat hippocampus: Evidence that hydroxynonenal formation precedes neuronal cell death. Free Radic Biol Med. 2000; 28:1214-1221. [PubMed: 10889451]

Oubidar M, Boquillon M, Marie C, Bouvier C, Beley A, Bralet J. Effect of intracellular iron loading on lipid peroxidation of brain slices. Free Radic. Biol. Med. 1996; 21:763-769. [PubMed: 8902522]

Oury TD, Piantadosi CA, Crapo JD. Cold-induced brain edema in mice. Involvement of extracellular superoxide dismutase and nitric oxide. J. Biol. Chem. 1993; 268:15394-15398. [PubMed: 7687996]

Oztaş B, Kiliç S, Dural E, Ispir T. Influence of antioxidants on the blood-brain barrier permeability during epileptic seizures. J. Neurosci. Res. 2001; 66:674-678. [PubMed: 11746387]

Packer L. Antioxidant properties of lipoic acid and its therapeutic effects in prevention of diabetes complications and cataracts. Ann. N. Y. Acad. Sci. 1994; 738:257-264. [PubMed: 7832436]

Packer L, Witt EH, Tritschler HJ. alpha-Lipoic acid as a biological antioxidant. Free Radic. Biol. Med. 1995; 19:227-250. [PubMed: 7649494]

Pagonopoulou O, Angelatou F. Time development and regional distribution of $[3 \mathrm{H}]$ nitrobenzylthioinosine adenosine uptake site binding in the mouse brain after acute Pentylenetetrazol-induced seizures. J. Neurosci. Res. 1998; 53:433-442. [PubMed: 9710263]

Patel M. Mitochondrial dysfunction and oxidative stress: cause and consequence of epileptic seizures. Free Radic. Biol. Med. 2004; 37:1951-1962. [PubMed: 15544915]

Patel M, Ardelt BK, Yim GK, Isom GE. Interaction of trimethyltin with hippocampal glutamate. Neurotoxicology. 1990; 11:601-608. [PubMed: 2128396]

Patel M, Liang LP, Robert LJ. Enhanced hippocampal F2-isoprostane formation following kainiteinduced seizures. J. Neurochem. 2001; 79:1065-1070. [PubMed: 11739620]

Patel BN, Dunn RJ, Jeong SY, Zhu Q, Julien JP, David S. Ceruloplasmin regulates iron levels in the CNS and prevents free radical injury. J. Neurosci. 2002; 22:6578-6586. [PubMed: 12151537]

Patsoukis N, Zervoudakis G, Georgiou CD, Angelatou F, Matsokis NA, Panagopoulos NT. Effect of pentylenetetrazol-induced epileptic seizure on thiol redox state in the mouse cerebral cortex. Epilepsy Res. 2004a; 62:65-74. [PubMed: 15519133]

Patsoukis N, Zervoudakis G, Panagopoulos NT, Georgiou CD, Angelatou F, Matsokis NA. Thiol redox state (TRS) and oxidative stress in the mouse hippocampus after pentylenetetrazol-induced epileptic seizure. Neurosci. Lett. 2004b; 357:83-86. [PubMed: 15036580] 
Pazdernik TL, Emerson MR, Cross R, Nelson SR, Samson FE. Soman-induced seizures: limbic activity, oxidative stress and neuroprotective proteins. J. Appl. Toxicol. 2001; 21:S87-94. [PubMed: 11920927]

Perry G, Nunomura A, Hirai K, Zhu X, Perez M, Avila J, Castellani RJ, Atwood CS, Aliev G, Sayre LM, Takeda A, Smith MA. Is oxidative damage the fundamental pathogenic mechanism of Alzheimer's and other neurodegenerative disease? Free Radic. Biol. Med. 2002; 33:1475-1479. [PubMed: 12446204]

Raju GB, Behari M, Prasad K, Ahuja GK. Randomized, double-blind, placebo-controlled, clinical trial of D-alpha-tocopherol (vitamin E) as add-on therapy in uncontrolled epilepsy. Epilepsia. 1994; 35:368-372. [PubMed: 8156959]

Ramaekers VT, Calomme M, Vanden Berghe D, Makropoulos W. Selenium deficiency triggering intractable seizures. Neuropediatrics. 1994; 25:217-223. [PubMed: 7824095]

Ramsay RE, Rowan AJ, Pryor FM. Special considerations in treating the elderly patient with epilepsy. Neurology. 2004; 62:S24-S29. [PubMed: 15007161]

Rao CV. Regulation of COX and LOX by curcumin. Adv. Exp. Med. Biol. 2007; 595:213-226. [PubMed: 17569213]

Rauca C, Zerbe R, Jantze H. Formation of free hydroxyl radicals after pentylenetetrazol-induced seizure and kindling. Brain Res. 1999; 847:347-351. [PubMed: 10575107]

Rauca C, Wiswedel I, Zerbe R, Keilhoff G, Krug M. The role of superoxide dismutase and alphatocopherol in the development of seizures and kindling induced by pentylenetetrazol - influence of the radical scavenger alpha-phenyl-N-tert-butyl nitrone. Brain Res. 2004; 1009:203-212. [PubMed: 15120598]

Rayman MP. The importance of selenium to human health. Lancet. 2000; 356:233-241. [PubMed: 10963212]

Richard D, rivest R, Huang Q, Bouillaud F, Sanchis D, Champigny O, Ricquier D. Distribution of the uncoupling protein 2 mRNA in the mouse brain. J Comp Neurol. 1998; 397:549-560. [PubMed: 9699915]

Rong Y, Baudry M. Seizure activity results in a rapid induction of nuclear factor-kB in aduclt but not juvenile rat limbic structures. J. Neurochem. 1996; 67:662-668. [PubMed: 8764593]

Rong Y, Doctrow SR, Tocco G, Baudry M. EUK-134, a synthetic superoxide dismutase and catalase mimetic, prevents oxidative stress and attenuates kainate-induced neuropathology. Proc. Natl. Acad. Sci. U. S. A. 1999; 96:9897-9902. [PubMed: 10449791]

Rotruck JT, Pope AL, Ganther HE, Swanson AB, Hafeman DG, Hoekstra WG. Selenium: biochemical role as a component of glutathione peroxidase. Science. 1973; 179:588-590. [PubMed: 4686466]

Ryu JR, Shin CY, Park KH, Jeon GS, Kim HC, Kim WK, Dailey JW, Jobe PC, Cho SS, Ko KH. Effect of repeated seizure experiences on tyrosine hydroxylase immunoreactivities in the brain of genetically epilepsy-prone rats. Brain Res Bull. 2000; 53:777-782. [PubMed: 11179842]

Sadrzadeh SMH, Eaton JW. Hemoglobin-mediated oxidant damage to the central nervous system requires endogenous ascorbate. J. Clin. Invest. 1988; 82:1510-1515. [PubMed: 2846656]

Saija A, Princi P, Pisani A, lanza M, Scalese M, Aramnejad E, Ceserani R, Costa G. Protective effect of glutathione on kainic acid-induced neuropathological changes in the rat brain. Gen Pharmacol. 1994; 25:97-102. [PubMed: 8026720]

Santos LF, Freitas RL, Xavier SM, Saldanha GB, Freitas RM. Neuroprotective actions of vitamin C related to decreased lipid peroxidation and increased catalase activity in adult rats after pilocarpine-induced seizures. Pharmacol. Biochem. Behav. 2008; 89:1-5. [PubMed: 18096215]

Savaskan NE, Bräuer AU, Kühbacher M, Eyüpoglu IY, Kyriakopoulos A, Ninnemann O, Behne D, Nitsch R. Selenium deficiency increases susceptibility to glutamate-induced excitotoxicity. FASEB J. 2003; 17:112-114. [PubMed: 12424220]

Scapagnini G, Foresti R, Calabrese V, Giuffrida Stella AM, Green CJ, Motterlini R. Caffeic acid phenethyl ester and curcumin: a novel class of heme oxygenase-1 inducers. Mol. Pharmacol. 2002; 61:554-561. [PubMed: 11854435]

Schneider Oliveira M, Flávia Furian A, Freire Royes LF, Rechia Fighera M, de Carvalho Myskiw J, Gindri Fiorenza N, Mello CF. Ascorbate modulates pentylenetetrazol-induced convulsions biphasically. Neuroscience. 2004; 128:721-728. [PubMed: 15464280] 
Schreck R, Albermann K, Baurele PA. Nuclear factor kappa B: an oxidative stress-responsive transcription factor of eukaryotic cells. Free Rad Res Commun. 1992; 17:221-237.

Schreck R, Rieber P, Baeuerle PA. Reactive oxygen intermediates as apparently widely used messengers in the activation of the NF-kappa B transcription factor and HIV-1. EMBO J. 1991; 10:2247-2258. [PubMed: 2065663]

Schulpis KH, Lazaropoulou C, Regoutas S, Karikas GA, Margeli A, Tsakiris S, Papassotiriou I. Valproic acid monotherapy induces DNA oxidative damage. Toxicology. 2006; 217:228-232. [PubMed: 16289809]

Schweizer U, Bräuer AU, Köhrle J, Nitsch R, Savaskan NE. Selenium and brain function: a poorly recognized liaison. Brain Res. Brain Res. Rev. 2004; 245:164-178. [PubMed: 15210302]

Shafiq N, Malhotra S, Pandhi P. Anticonvulsant action of cerecoxib (alone and incombination with sub-threshold dose of phenytoin) in electroshock induced convulsion. Methods Find Exp Clin Pharmacol. 2003; 25:87-90. [PubMed: 12731453]

Shin EJ, Jhoo JH, Jhoo WK, Lee C, Jung BD, Kim HC. Protection against kainate neurotoxicity by pyrrolidine dithiocarbonate. Clin. Exp. Pharmacol, Physiol. 2004; 31:320-326. [PubMed: 15191405]

Shin EJ, Suh SK, Lim YK, Jhoo WK, Hjelle OP, Ottersen OP, Shin CY, Ko KH, Kim WK, Kim DS, Chun W, Ali S, Kim HC. Ascorbate attenuates trimethyltin-induced oxidative burden and neuronal degeneration in the rat hippocampus by maintaining glutathione homeostasis. Neuroscience. 2005; 133:715-727. [PubMed: 15908128]

Shin HJ, Lee JY, Son E, Lee DH, Kim HJ, Kang SS, Cho GJ, Choi WS, Roh GS. Curcumin attenuates the kainic acid-induced hippocampal cell death in the mice. Neurosci. Lett. 2007; 416:49-54. [PubMed: 17300872]

Shin EJ, Jeong JH, Bing G, Park ES, Chae JS, Yen TP, Kim WK, Wie MB, Jung BD, Kim HJ, Lee SY, Kim HC. Kainate-induced mitochondrial oxidative stress contributes to hippocampal degeneration in senescence-accelerated mice. Cell. Signal. 2008a; 20:645-658. [PubMed: 18248956]

Shin EJ, Ko KH, Kim WK, Chae JS, Yen TP, Kim HJ, Wie MB, Kim HC. Role of glutathione peroxidase in the ontogeny of hippocampal oxidative stress and kainate seizure sensitivity in the genetically epilepsy-prone rats. Neurochem. Int. 2008b; 52:1134-1147. [PubMed: 18226427]

Shin EJ, Jeong JH, Chung YH, Kim TW, Shin CY, Kim WK, Ko KH, Kim HC. Decrease in the kainite-induced wet dog shake behaviours in the genetically epilepsy-prone rats: possible involvement of an impaiored synaotic transmission to the 5-HT2A receptor. J. Pharmacol Sci. 2009a; 110:401-404. [PubMed: 19609070]

Shin EJ, Jeong JH, Kim AY, Koh YH, Nah SY, Kim WK, Ko KH, Kim HJ, Wie MB, Kwon YS, Yoneda Y, Kim HC. Protection against kainate neurotoxicity by ginsenosides: attenuation of convulsive behavior, mitochondrial dysfunction, and oxidative stress. J. Neurosci. Res. 2009b; 87:710-722. [PubMed: 18816793]

Shin EJ, Koh YH, Kim AY, Nah SY, Jeong JH, Chae JS, Kim SC, Yen TP, Yoon HJ, Kim WK, Ko $\mathrm{KH}$, Kim HC. Ginsenosides attenuate kainic acid-induced synaptosomal oxidative stress via stimulation of adenosine $\mathrm{A}(2 \mathrm{~A})$ receptors in rat hippocampus. Behav. Brain Res. 2009c; 197:239-245. [PubMed: 18809438]

Shivakumar BR, Anandatheerthavarada HK, Ravindranath V. Free radical scavenging systems in developing rat brain. Int. J. Dev. Neurosci. 1991; 9:181-185. [PubMed: 2058419]

Shoham S, Youdim MB. Nutritional iron deprivation attenuates kainate-induced neurotoxicity in rats: implications for involvement of iron in neurodegeneration. Ann. N. Y. Acad. Sci. 2004; 1012:94-114. [PubMed: 15105258]

Simmet T, Seregi A, Hertting G. Characterization of seizure-induced cysteinyl-leukotriene formation in brain tissue of convulsion-prone gerbils. J. Neurochem. 1988; 50:1738-1742. [PubMed: 2836558]

Sloviter RS. The neurobiology of temporal lobe epilepsy: too much information, not enough knowledge. Comptes Rendus Biol. 2005; 328:143-153. 
Sloviter RS, von Knebel Doeberitz C, Walsh TJ, Dempster DW. On the role of seizure activity in the hippocampal damage produced by trimethyltin. Brain Res. 1986; 367:169-182. [PubMed: 3697698]

Sobaniec W, Kulak W, Sobaniec H, Farbiszewski R, Drozdowski W. Effects of clobazam and vitamin E on the lipid peroxidation in the rat brain after electroconvulsive shock. Rocz. Akad. Med. Bialymst. 1999; 44:134-140. [PubMed: 10697428]

Solmaz I, Gürkanlar D, Gökçil Z, Göksoy C, Ozkan M, Erdoğan E. Antiepileptic activity of melatonin in guinea pigs with pentylenetetrazol-induced seizures. Neurol. Res. 2009; 31:989-995. [PubMed: 19138464]

Sperk G. Kainic acid seizures in the rat. Prog. Neurobiol. 1994; 42:1-32. [PubMed: 7480784]

Stadtman ER. Protein oxidation in aging and age-related diseases. Ann. N.Y. Acad. Sci. 2001; 928:2238. [PubMed: 11795513]

Strine TW, Kobau R, Chapman DP, Thurman DJ, Price P, Balluz LS. Psychological distress, comorbidities and health behaviours among U.S. adults with seizures: results from the 2002 National Health Interview Survey. Epilepsia. 2005; 46:1133-1139. [PubMed: 16026567]

Sudha K, Rao AV, Rao A. Oxidative stress and antioxidants in epilepsy. Clin. Chim. Acta. 2001; 303:19-24. [PubMed: 11163018]

Sullivan PG, Dube C, Dorenbos K, Steward O, Baram TZ. Mitochondrial uncoupling protein-2 protects the immature brain from excitotoxic neuronal death. Ann. Neurol. 2003; 53:711-717. [PubMed: 12783416]

Sumanont Y, Murakami Y, Tohda M, Vajragupta O, Watanabe H, Matsumoto K. Prevention of kainic acid-induced changes in nitric oxide level and neuronal cell damage in the rat hippocampus by manganese complexes of curcumin and diacetylcurcumin. Life Sci. 2006; 78:1884-1891. [PubMed: 16266725]

Takeda T, Hosokawa M, Higuchi K, Hosono M, Akiguchi I, Katoh H. A novel murine model of aging, Senescence-Accelerated Mouse (SAM). Arch. Gerontol. Geriatr. 1994; 19:185-192. [PubMed: 15374284]

Tang L, Reiter RJ, Li ZR, Ortiz GG, Yu BP, Garcia JJ. Melatonin reduces the increase in 8-hydroxydeoxyguanosine levels in the brain and liver of kainic acid-treated rats. Mol. Cell Biochem. 1998; 178:299-303. [PubMed: 9546613]

Tejada S, Sureda A, Roca C, Gamundi A, Esteban S. Antioxidant response and oxidative damage in brain cortex after high dose of pilocarpine. Brain Res. Bull. 2007; 71:372-375. [PubMed: 17208654]

Tomé AR, Feng D, Freitas RM. The effects of alpha-tocopherol on hippocampal oxidative stress prior to in pilocarpine-induced seizures. Neurochem. Res. 2010; 35:580-587. [PubMed: 19941068]

Troadec JD, Marien M, Darios F, Hartmann A, Ruberg M, Colpaert F, Michel PP. Noradrenaline provides long-term protection to dopaminergic neurons by reducing oxidative stress. J. Neurochem. 2001; 79:200-210. [PubMed: 11595772]

Turrens JF, Freeman BA, Levitt JG, Crapo JD. The effects of hyperoxia on superoxide production by lung submitochondria particles. Arch Biochem Bipophys. 1982; 217:401-410.

Turski WA, Cavalheiro EA, Schwarz M, Czuczwar SJ, Kleinrok Z, Turski L. Limbic seizures produced by pilocarpine in rats: behavioural, electroencephalographic and neuropathological study. Behav. Brain Res. 1983; 9:315-335. [PubMed: 6639740]

Ueda Y, Doi T, Tokumaru J, Nakajima A, Nagatomo K. In vivo Evaluation of the effect of zonisamide on the hippocampal redox state during kainic acid-induced seizure status in rats. Neurochem. Res. 2005; 30:1117-1121. [PubMed: 16292504]

Van Den Pol AN, Obrietan K, Belousov A. Glutamate hyperexcitability and seizure-like activity throughout the brain and spinal cord upon relief from chronic glutamate receptor blockade in culture. Neuroscience. 1996; 74:653-674. [PubMed: 8884763]

Varoglu AO, Yildirim A, Aygul R, Gundogdu OL, Sahin YN. Effects of valproate, carbamazepine, and levetiracetam on the antioxidant and oxidant systems in epileptic patients and their clinical importance. Clin. Neuropharmacol. 2010; 33:155-157. [PubMed: 20502135] 
Veinbergs I, Mallory M, Sagara Y, Masliah E. Vitamin E supplementation prevents spatial learning deficits and dendritic alterations in aged apolipoprotein E-deficient mice. Eur. J. Neurosci. 2000; 12:45414-45416.

Verrotti A, Basciani F, Trotta D, Pomilio MP, Morgese G, Chiarelli F. Serum copper, zinc, selenium, glutathione peroxidase and superoxide dismutase levels in epileptic children before and after 1 year of sodium valproate and carbamazepine therapy. Epilepsy Res. 2002; 48:71-75. [PubMed: 11823111]

Visioli F, Rodriguez de Turrco EB, Kreisman NR, Bazan NG. Membrane lipid degradation is related to interictal cortical activity in a series of seizures. Metab. Brain Dis. 1994; 9:161-170. [PubMed: 8072464]

Waldbaum S, Patel M. Mitochondria, oxidative stress, and temporal lobe epilepsy. Epilepsy Res. 2010; 88:23-45. [PubMed: 19850449]

Wallace DC, Zheng X, Lott MT, Shoffner JM, Hodge JA, Kelly RI, Epstein CM, Hopkins LC. Familal mitochondrial encephalomyopathy (Merrf): genetic, pathophysiological and biochemical characterization of a mitochondrial DNA disease. Cell. 1988; 55:601-610. [PubMed: 3180221]

Wang XS, Ong WY, Connor JR. Increase in ferric and ferrous iron in the rat hippocampus with time after kainate-induced excitotoxic injury. Exp. Brain Res. 2002; 143:137-148. [PubMed: 11880890]

Waterhouse EJ, DeLorennzo RJ. Status epilepticus in order patients. Epidemiology and treatment options. Drugs Aging. 2001; 18:133-142. [PubMed: 11346127]

Weber GF, Maertens P, Meng XZ, Pippenger CE. Glutathione peroxidase deficiency and childhood seizures. Lancet. 1991; 337:1443-1444. [PubMed: 1675321]

Wheless JW, Neto W, Wang S, EPMN-105 Study Group. Topiramate, carbamazepine, and valproate monotherapy: double-blind comparison in children with newly diagnosed epilepsy. J. Child Neurol. 2004; 19:135-141. [PubMed: 15072107]

Wie MB, Cho YJ, Jhoo WK, Kim HC. Phenidone attenuates oxygen/glucose deprivation-induced neurotoxicity by antioxidant and antiapoptotic action in mouse cortical cultures. Neurosci. Lett. 1999; 272:91-94. [PubMed: 10507549]

Willmore LJ, Rubin JJ. Antiperoxidant pretreatment and iron-induced epileptiform discharges in the rat: EEG and histopathologic studies. Neurology. 1981; 31:63-69. [PubMed: 7192826]

Willmore LJ, Sypert GW, Munson JB. Recurrent seizures induced by cortical iron injection: a model of posttraumatic epilepsy. Ann. Neurol. 1978; 4:329-336. [PubMed: 103489]

Winyard PG, Mody CJ, Hacob C. Oxidative activation of antioxidant defense. Trends Biochem. Sci. 2005; 30:453-461. [PubMed: 15996871]

Wong-ekkabut J, Xu Z, Triampo W, Tang IM, Tieleman DP, Monticelli L. Effect of lipid peroxidation of lipid bilayers: A molecular dynamic study. Biophys. J. 2007; 93:4225-4236. [PubMed: 17766354]

Wozniak DF, Stewart GR, Miller JP, Olney JW. Age-related sensitivity to kainate neurotoxicity. Exp. Neurol. 1991; 114:250-253. [PubMed: 1748199]

Yamamoto HA, Mohanan PV. Ganglioside GT1B and melatonin inhibit brain mitochondrial DNA damage and seizures induced by kainic acid in mice. Brain Res. 2003; 964:100-106. [PubMed: 12573517]

Yiş U, Seçkin E, Kurul SH, Kuralay F, Dirik E. Effects of epilepsy and valproic acid on oxidant status in children with idiopathic epilepsy. Epilepsy Res. 2009; 84:232-237. [PubMed: 19261443]

Yoneda Y, Kuramoto N, Kitayama T, Hinoi E. Consolidation of transient ionotropic glutamate signals through nuclear transcription factors in the brain. Prog. Neurobiol. 2001; 63:697-719. [PubMed: 11165002]

Yüksel A, Cengiz M, Seven M, Ulutin T. Erythrocyte glutathione, glutathione peroxidase, superoxide dismutase and serum lipid peroxidation in epileptic children with valproate and carbamazepine monotherapy. J. Basic Clin. Physiol. Pharmacol. 2000; 11:73-81. [PubMed: 10851665]

Zuchora B, Turski WA, Wielosz M, Urbanska EM. Protective effect of adenosine receptor agonists in a new model of epilepsy--seizures evoked by mitochondrial toxin, 3-nitropropionic acid, in mice. Neurosci. Lett. 2001; 305:91-94. [PubMed: 11376891] 
(A) SOD-1 activity

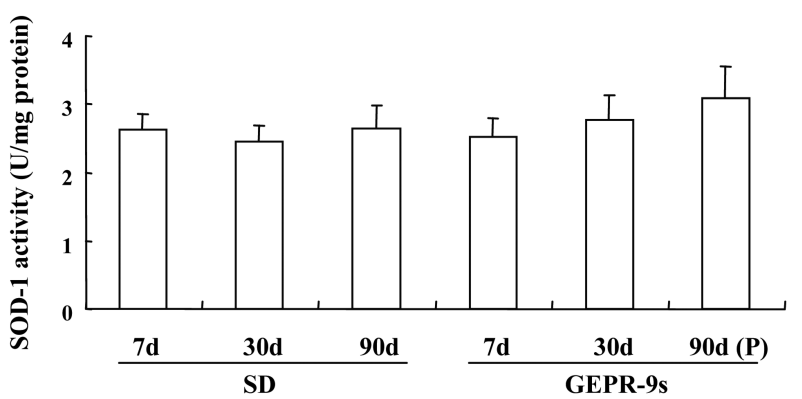

(B) SOD-2 activity

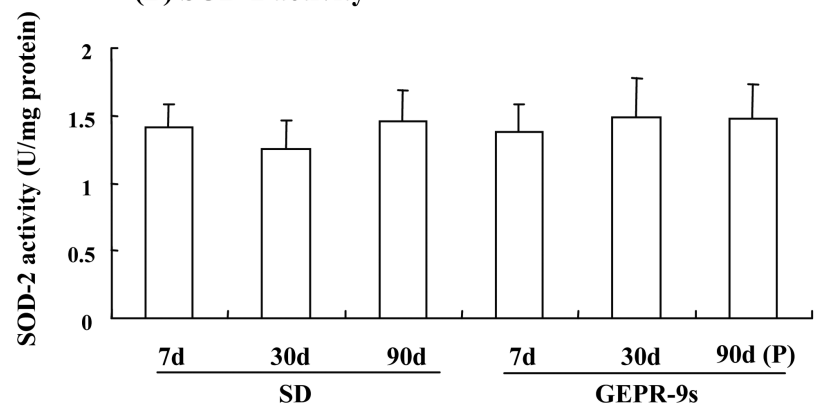

(C) GPx activity

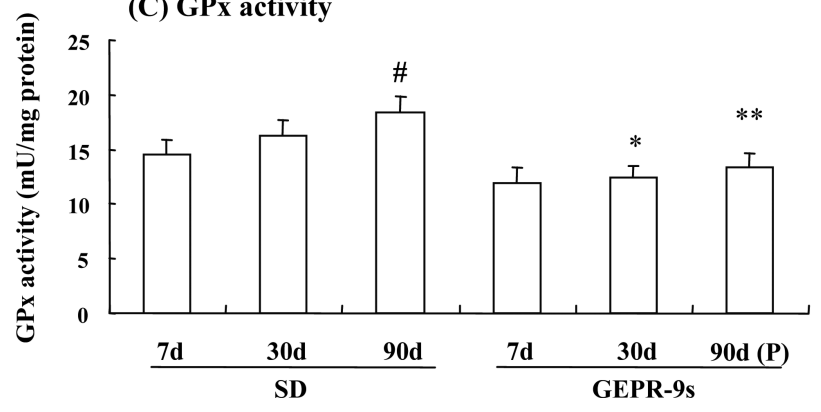

(D) GSH and GSSG

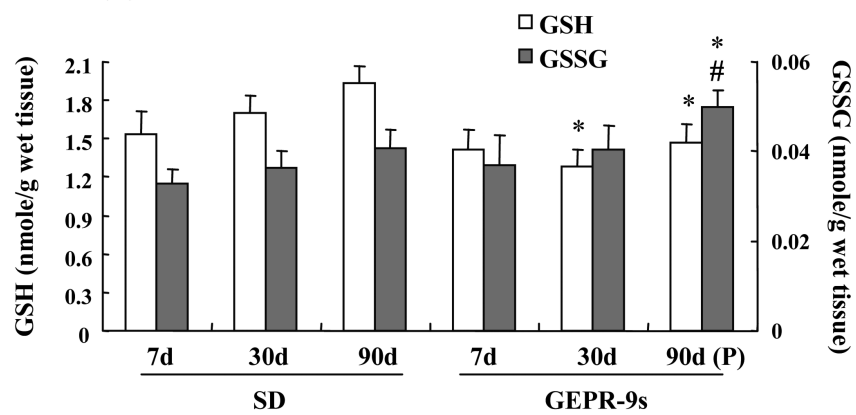

(E) GSH/ GSSG

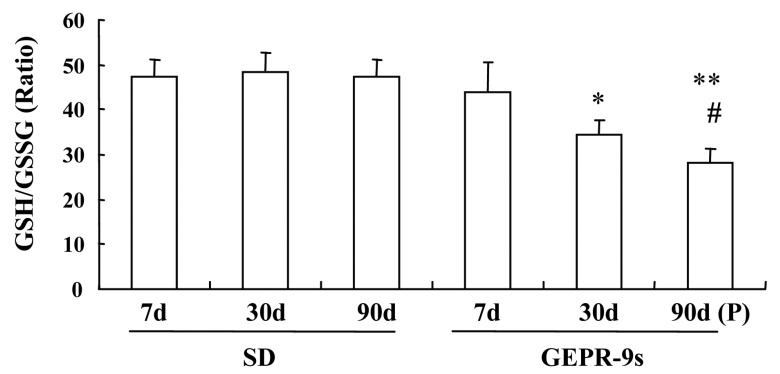

(F) MDA and Protein carbonyl

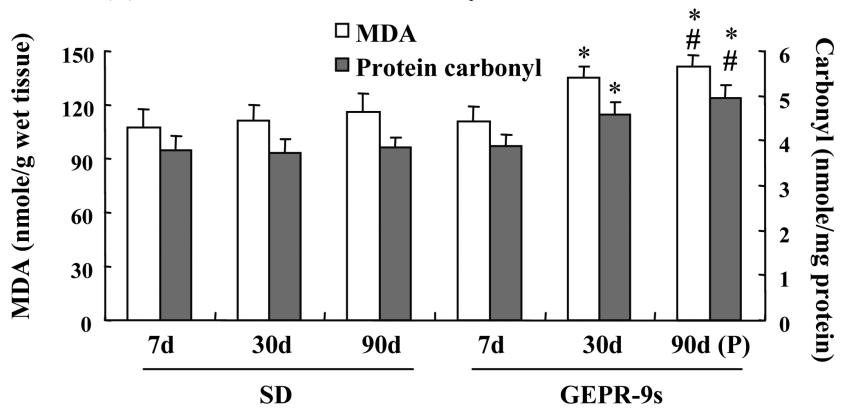

Fig. 1.

Changes in the enzymatic (A, B, and C)- and non-enzymatic (D and E)-antioxidant status, and oxidative stress markers (F) in the hippocampus of GEPR-9s and SD rats at post-natal days (P) 7, 30, and 90. Each value is the mean \pm S.E.M. of 8 animals. ${ }^{\#} P<0.05$ vs. SD $7 \mathrm{~d}$, ${ }^{*} P$ $<0.05, * * P<0.01$ vs. corresponding time point of SD (one-way ANOVA with Fischer's PLSD test) (from Shin et al., 2008b). 
A. Nissl

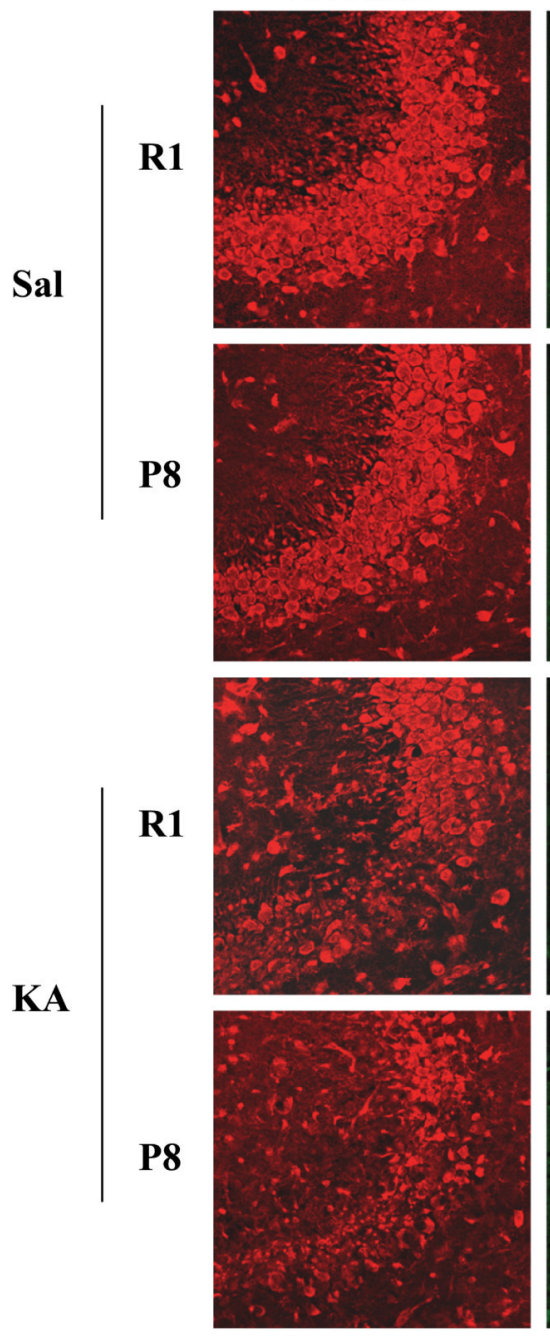

B. FJ
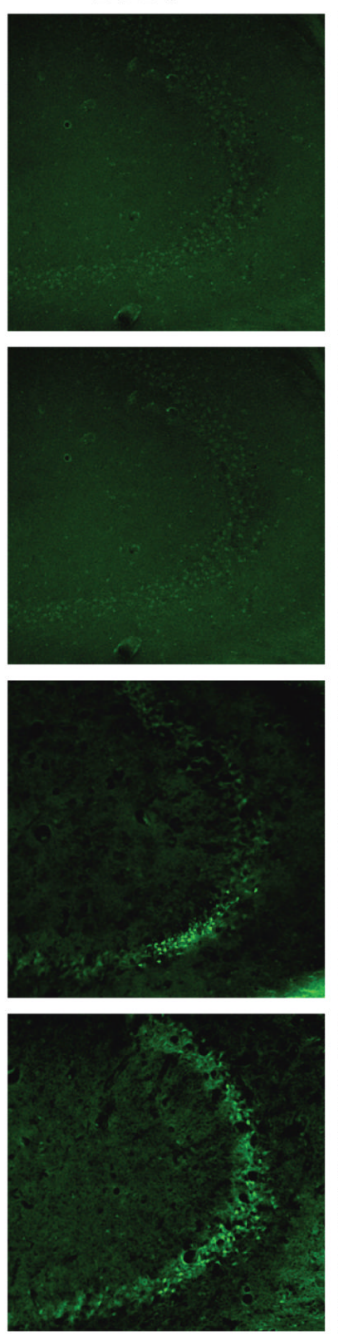

B.
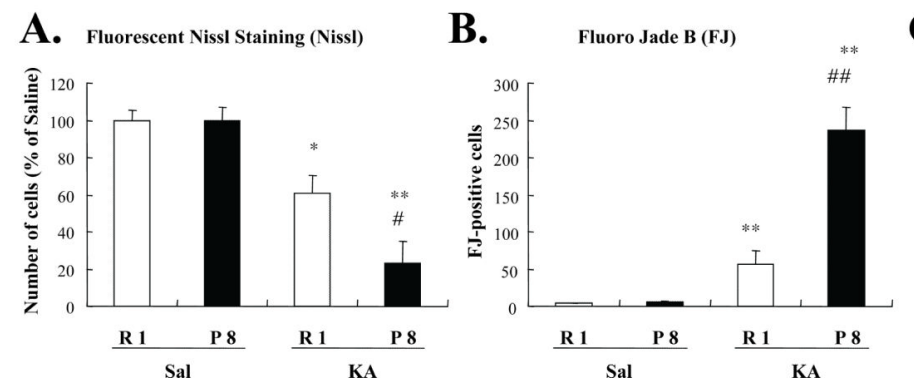

C. EM
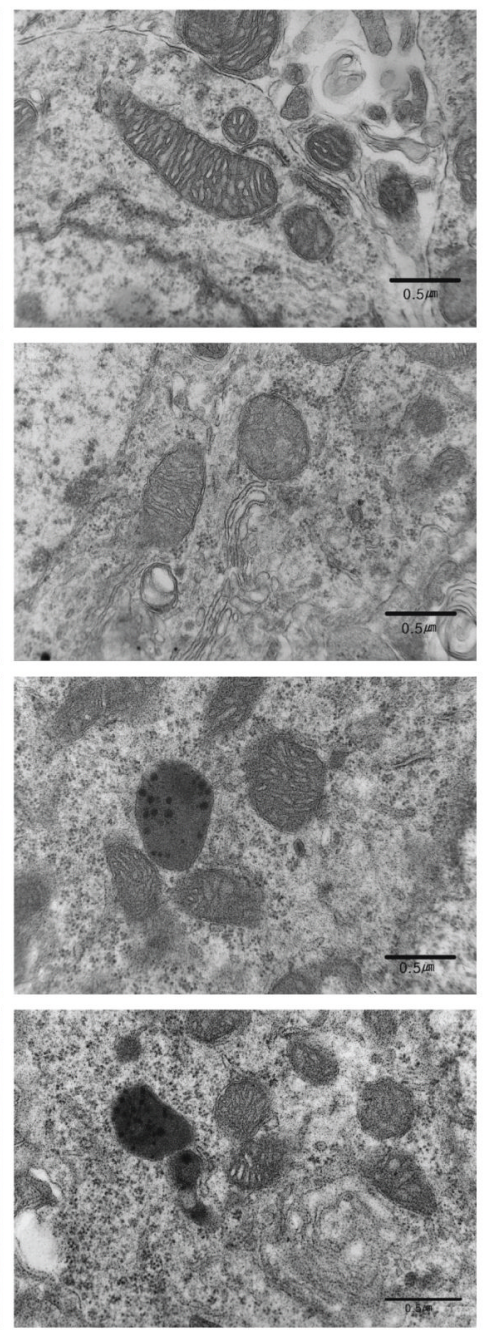

C. Electromicroscopic changes (EM)

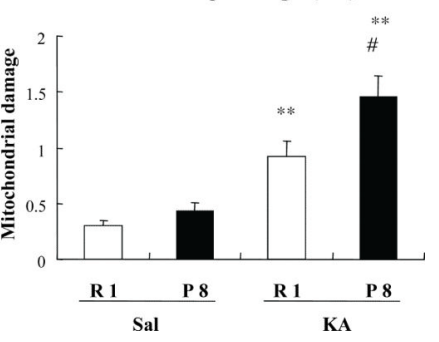

Fig. 2.

Representative photomicrographs of fluorescent Nissl staining (A), Fluoro Jade B staining (B), and ultrastructural changes (C) in the CA3 region of the hippocampi from SAM-R1 and SAM-P8 mice after KA administration. A semi-quantitative evaluation of 20 electron micrographs was performed (column graph). To evaluate mitochondrial abnormalities, a three-stage scoring method was adopted: Grade 0 , no evidence of mitochondrial abnormalities; Grade 1, abnormal shapes of mitochondria and/or partial disruption of cristae and matrix swelling; and Grade 2, loss of cristae and matrix, with multiple electron-dense deposits. Electron micrographs of hippocampal neuronal cells, showing effacement of the mitochondrial matrix with electron-dense granule deposits and normal-sized mitochondria. 
Electron micrographs of mitochondria from mouse hippocampus. Note intense electrondense material in the mitochondria and lipofuscin granules in the cytoplasm of SAM-P8 mice after KA administration. Moderately electron-dense material in the mitochondria without lipofuscin granules in the cytoplasm appears in the SAM-R1 mice $3 \mathrm{~h}$ after KA administration. There was no significant morphological difference between SAM-R1 and SAM-P8 mice without KA. Each value indicates mean \pm S.E.M. of 6 animals. $* P<0.05$, ** $P<0.01$ vs. corresponding Sal, ${ }^{\#} P<0.05,{ }^{\# \#} P<0.01$ vs. corresponding SAM-R1 mice (ANOVA with Fischer's PLSD test) (from Shin et al., 2008a). 
Table 1

Effects of antiepileptic drugs on the parameters of antioxidant and oxidative stress in the blood of the epileptic patients.

\begin{tabular}{|c|c|c|c|c|}
\hline Antiepileptic drug & Findings & & Materials & Subject and reference \\
\hline \multirow[t]{20}{*}{ Valproic acid } & Lipid peroxidation & $\uparrow$ & Erythrocytes & Childhood Yiş et al., 2009 \\
\hline & & $\uparrow$ & Plasma & Adolescent and adult Hamed et a1., 2004 \\
\hline & & $\uparrow$ & Serum & Childhood Yüksel et al., 2000; Schulpis et al., 2006 \\
\hline & 8-OHdG & $\uparrow$ & Serum & Childhood Schulpis et a1., 2006 \\
\hline & & $\uparrow$ & Leukocytes & Adult Varoglu et al., 2010 \\
\hline & Total antioxidant capacity & $\downarrow$ & Serum & Childhood Schulpis et a1., 2006 \\
\hline & & $\downarrow$ & Plasma & Adolescent and adult Hamed et a1., 2004 \\
\hline & SOD & $\downarrow$ & Erythrocytes & Adult Niketić et al. 1995 \\
\hline & & - & Erythrocytes & Adult Verrotti et al., 2002 \\
\hline & & $\uparrow$ & Erythrocytes & Childhood Yüksel et a1., 2000 \\
\hline & GPx & $\downarrow$ & Erythrocytes & Adult Niketić et al. 1995 \\
\hline & & & & Childhood Yüksel et a1., 2000 \\
\hline & & $\downarrow \%$ & Erythrocytes & Childhood Graf et al., 1998 \\
\hline & & - & Erythrocytes & Adult Verrotti et al., 2002 \\
\hline & & $\uparrow$ & Plasma & Adolescent and adult Hamed et al., 2004 \\
\hline & GR & & Erythrocytes & Childhood Sobaniec et a1., 2006 \\
\hline & & $\uparrow \%$ & Erythrocytes & Childhood Graf et al., 1998 \\
\hline & $\mathrm{Se}$ & $\downarrow \%$ & Serum & Childhood Graf et al., 1998 \\
\hline & & - & Serum & Adult Verrotti et al., 2002 \\
\hline & & $\uparrow$ & Serum & Adolescent and adult Hamed et al., 2004 \\
\hline \multirow[t]{5}{*}{ Phenytoin } & Lipid peroxidation & $\uparrow$ & Serum & Adult Liu et a1., 1998 \\
\hline & & & & Uncertain Mahle and Dasgupta, 1997 \\
\hline & Total antioxidant capacity & $\downarrow$ & Serum & Uncertain Mahle and Dasgupta, 1997 \\
\hline & SOD & $\uparrow$ & Serum & Adult Liu et a1., 1998 \\
\hline & GSH & $\downarrow$ & Serum & Adult Liu et a1., 1998 \\
\hline \multirow[t]{4}{*}{ Carbamazepine } & Lipid peroxidation & $\uparrow$ & Plasma & Adolescent and adult Hamed et a1., 2004 \\
\hline & & $\downarrow$ & Erythrocytes & Childhood Sobaniec et a1., 2006 \\
\hline & & - & Serum & Childhood Yüksel et a1., 2000 \\
\hline & Total peroxide & $\uparrow$ & Plasma & Childhood Aycicek and Iscan, 2007 \\
\hline
\end{tabular}

Neurochem Int. Author manuscript; available in PMC 2013 March 23. 


\begin{tabular}{|c|c|c|c|c|}
\hline \multirow[t]{2}{*}{ Antiepileptic drug } & \multicolumn{2}{|l|}{ Findings } & \multirow{2}{*}{$\frac{\text { Materials }}{\text { Leukocytes }}$} & \multirow{2}{*}{$\begin{array}{l}\text { Subject and reference } \\
\text { Adult Varoglu et al., } 2010\end{array}$} \\
\hline & 8-OHdG & $\uparrow$ & & \\
\hline & Total antioxidant capacity & $\downarrow$ & Plasma & Adolescent and adult Hamed et a1., 2004 \\
\hline & SOD & $\downarrow$ & Erythrocytes & Adult Niketić et al. 1995 \\
\hline & & - & Erythrocytes & Adult Verrotti et al., 2002 \\
\hline & & & & Childhood Yüksel et a1., 2000 \\
\hline & & $\downarrow$ & Serum & Adult Liu et a1., 1998 \\
\hline & GPx & $\downarrow$ & Erythrocytes & Adult Niketić et al. 1995 \\
\hline & & - & Erythrocytes & Adult Verrotti et al., 2002 \\
\hline & & & & Childhood Yüksel et a1., 2000 \\
\hline & & - & Plasma & Adolescent and adult Hamed et a1., 2004 \\
\hline & CAT & $\downarrow$ & Erythrocytes & Adult Niketic et al. 1995 \\
\hline & $\mathrm{Se}$ & - & Erythrocytes & Adult Verrotti et al., 2002 \\
\hline & & - & Plasma & Adolescent and adult Hamed et a1., 2004 \\
\hline \multirow[t]{2}{*}{ Phenobarbital } & Lipid hydroperoxide & $\uparrow$ & Plasma & Childhood Aycicek and Iscan, 2007 \\
\hline & SOD/GPx & $\downarrow$ & Erythrocytes & Adult Niketić et al. 1995 \\
\hline Levetiracetam & 8-OHdG & $\uparrow$ & Leukocytes & Adult Varoglu et al., 2010 \\
\hline
\end{tabular}

$\%$ Only in patients with a severe adverse experience related to valproic acid therapy. 